\title{
PRESENCIA DEL ESCRIBANO EN LA EXTREMADURA DE FINALES DE LA EDAD MODERNA A TRAVÉS DEL INTERROGATORIO DE LA REAL AUDIENCIA
}

\author{
Carmen Solano Macías* \\ Facultad de Ciencias de la Documentación y la Comunicación. Universidad de Extremadura. \\ Agustín Vivas Moreno** \\ Facultad de Ciencias de la Documentación y la Comunicación. Universidad de Extremadura.
}

\begin{abstract}
Resumen: El artículo parte de una breve revisión de los escribanos en España a finales del siglo XVIII, para enfocarse posteriormente en el análisis de dichos oficiales en la Extremadura de la época. La fuente documental en la que nos basamos es el interrogatorio que llevó a cabo la Real Audiencia de Extremadura en 1791 a todas las poblaciones que estaban bajo su jurisdicción, buscando la información necesaria para llevar a cabo sus funciones. Los datos sobre escribanos y fieles de fechos que proporcionan las respuestas a este cuestionario nos permiten analizar asuntos como su presencia en los pueblos extremeños, las labores que realizaban, el salario que recibían o su ética profesional. La metodología utilizada se basa en el análisis documental de los textos del interrogatorio que tratan sobre los escribanos mediante la creación de un sistema de información histórica, junto con el análisis histórico de los mismos. Todo ello nos permite mostrar un panorama preciso de estos profesionales en las diferentes demarcaciones que entonces componían Extremadura.
\end{abstract}

Palabras clave: Escribanos; Extremadura; historia; interrogatorios; Real Audiencia de Extremadura; siglo XVIII.

Title: PRESENCE OF THE PUBLIC NOTARY IN EXTREMADURA AT THE END OF MODERN AGE THROUGH THE INTERROGATION OF THE REAL AUDIENCIA.

Abstract: The work is based on the analysis of the public notaries in Spain at the end of Modern Age, to focus, later, on his study within Extremadura. To do this work, we rely on the documentation of the interrogation conducted by the Real Audiencia (Royal Court) of Extremadura to all the towns of the province in the year 1791, in order to obtain sufficient information to carry out its functions. This questionnaire, among other topics, provides significant information about the notaries public and the fieles de fechos -which replaced the notary in many populations- which allows us to analyze issues such as their presence in the different populations, the tasks they performed, the salary they received, or their professional ethics. For this, a methodology of documentary analysis of the texts obtained through the use of a historical information system created to the object has been followed. All this allows us to show an accurate view of these professionals in the different parties that then composed Extremadura. Keywords: Notaries; Extremadura; history; interrogations; Real Audiencia de Extremadura; XVIII century.

Copyright: () 2019 Servicio de Publicaciones de la Universidad de Murcia (Spain). Este es un artículo de acceso abierto distribuido bajo los términos de la licencia Creative Commons Reconocimiento 4.0 Internacional (CC BY 4.0).

\section{INTRODUCCIÓN: LOS ESCRIBANOS Y FIELES DE FECHOS EN LA ESPAÑA DEL SIGLO XVIII}

Al llegar al poder la monarquía borbónica, y como consecuencia de su interés por organizar la administración y dejar constancia por escrito de todos los actos administrativos como testimonio y prueba de los hechos, el oficio escribanil se hizo más necesario que nunca para sectores muy variados de la sociedad. Hemos de tener en cuenta que el Estado se había burocratizado, y la vida administrativa se regía por la máxima de que "lo que no estaba escrito carecía de valor legal". Los escribanos, oidores, letrados, alcaldes, etc. hicieron del documento escrito el eje central de los procedimientos administrativos e incluso de las decisiones políticas (Lorenzo Cadarso, 2001, p. 1). Así, numerosas gestiones debían estar obligatoriamente refrendadas por un escribano para conferirles valor legal. Este funcionario tenía una doble vertiente: por un lado escrituraria, cuando ejercía sus labores jurídicas en el ámbito privado, como la elaboración de testamentos, contratos, etc. ${ }^{1}$; y por otro actuaria, relacionada con su actuación en la administración municipal y en la justicia, como la sustanciación de los pleitos civiles y criminales (Aranda Pérez, 1999, p. 135). Por otra parte, los escribanos se consideran "los principales creadores de cultura escrita en la Edad Moderna" (Extremera Extremera, 2003, p. 205), ya que, por su actividad profesional, eran gestores y productores de documentos, tanto públicos como privados.

\footnotetext{
*csolano@unex.es

**aguvivas@unex.es

Recibido: 28-11-2018; $2^{a}$ versión: 14-02-2019; aceptado: 28-02-2019.
}

SOLANO MACÍAS, C. y VIVAS MORENO, A. Presencia del escribano en la Extremadura de finales de la Edad Moderna a través del interrogatorio de la Real Audiencia. Anales de Documentación, 2019, vol. 22, $\mathrm{n}^{\circ}$ 2. Disponible en: http://dx.doi.org/10.6018/analesdoc.351341. 
En la Edad Moderna, la población alfabetizada - es decir, la que dominaba las técnicas de lectura y de escritura- era minoritaria. La mayor parte de los ciudadanos debían recurrir, cuando les era necesario expresar o dejar constancia de algo, a esta minoría letrada (Bouza Álvarez, 1997, p. 26) de la que formaba parte el escribano ${ }^{2}$. Este, en su origen, era solamente una persona que sabía leer y escribir con corrección, inserta en una sociedad analfabeta (Reder Gadow, 1982, p. 195). Pero con el paso del tiempo se convirtió en un funcionario cuya responsabilidad principal era confirmar, a través de su firma o rúbrica, la veracidad de los documentos que pasaban ante él (Zozaya Montes, 2001, p. 27). Esta es la cualidad que realmente definía al escribano: su facultad autenticadora, por la cual el documento que redactaba adquiría carácter de instrumento público y tenía valor probatorio (Álvarez Coca, 1987, p. 555). También actuaban como conservadores de documentos, ya que tenían la obligación de custodiar los protocolos de sus escribanías por mandato real ${ }^{3}$.

El acceso a la profesión de escribano estaba regulado desde el reinado de Alfonso X el Sabio (Arribas Arranz, 1964, p. 170). Posteriormente, sucesivos monarcas fueron añadiendo condiciones que, en términos generales, tuvieron continuidad en el tiempo (Álvarez Coca, 1987, p. 196; Mendoza García, 2005, p. 408) ${ }^{4}$. Para conseguir su título debían superar un examen que probara su formación, que consistía en seguir estudios de gramática -fundamentalmente latinay otras disciplinas tradicionales (Castillo López, 2010, p. 357); más tarde perfeccionaban su aprendizaje trabajando durante un tiempo al servicio de un escribano en ejercicio, donde utilizaban libros técnicos y formularios profesionales (Extremera Extremera, 2001, p. 162). Los que no completaban su formación en una escribanía quedaban en simples profesionales de la escritura, como escribientes, copistas o amanuenses, y no tenían capacidad de otorgar fe pública de los documentos (Castillo López, 2010, p. 357).

Cózar Gutiérrez resume las obligaciones de los escribanos públicos -que no siempre se cumplían- en las siguientes: servir personalmente los oficios sin poder darlos en arrendamiento, guardar secreto sobre los actos que pasaban ante ellos, representar fielmente todo lo escrito y ser leales al rey, que era quien les había nombrado o confirmado como escribanos. En lo que se refería a su participación en la administración de justicia, debían evitar todo tipo de parcialidad en sus actuaciones (Cózar Gutiérrez, 2010, p. 281). Y, por normativa archivística dictada a secretarios y escribanos desde la época de los Reyes Católicos, tenían el deber de conservar la documentación en las propias oficinas, y no en sus domicilios particulares (Lorenzo Cadarso, 2001, p. 2).

Una figura estrechamente relacionada con el escribano era el fiel de fechos, que actuaba como sustituto de aquel en muchas poblaciones para dar "fe de los hechos". Este, a diferencia del escribano, no tenía que aprobar exámenes, obtener títulos ni cumplir requisito específico alguno más que ser honrado y saber leer y escribir con suficiente corrección.

\subsection{Clasificación de los escribanos}

La tipología de los escribanos puede establecerse según distintos criterios. Aquí nos referiremos solamente a los tipos que actuaban con mayor frecuencia en Extremadura a finales del siglo XVIII, y los clasificaremos por el territorio en el que podían ejercer su trabajo y por el tipo de trabajo que realizaban:

\subsubsection{Por el territorio en el que podían ejercer su trabajo}

- Escribanos del número o numerarios: eran los escribanos públicos adscritos a una ciudad. Cada población tenía la facultad de establecer el número de escribanos que considerase preciso para su vecindario (de ahí el nombre que recibían). Al haber un número fijo de escribanías, la única forma de acceder a una de ellas era por herencia, por compra o traspaso e incluso por alquiler, puesto que se consideraban bienes patrimoniales, transmisibles a otra persona siempre que reuniese los requisitos necesarios para ejercer el oficio.

- Escribanos reales o de los reinos: estaban autorizados a trabajar en todos los territorios del reino, excepto en los sitios en los que hubiera escribanos numerarios ejerciendo, pues estos tenían allí mayores competencias que los reales. Por ejemplo, los escribanos reales tenían prohibido por ley redactar escrituras notariales como titulares en aquellas poblaciones en las que hubiese escribanos numerarios, excepto si el titular estaba enfermo o ausente. El incumplimiento de esta norma por parte de algunos escribanos reales y otros hechos del mismo tipo fueron causa de reclamaciones y quejas por parte de los escribanos del número (Mendoza García, 2005, p. 410). En muchas ocasiones, los reales trabajaban como ayudantes en otras escribanías mientras esperaban una vacante en un puesto mejor.

- Escribanos de las órdenes: podían ejercer su oficio en los territorios de las órdenes militares, excepto donde hubiese escribanos del número. De manera similar a los escribanos de los reinos, en estos lugares tenían restringidas sus funciones, y dependían de los numerarios para realizar su trabajo. 


\subsubsection{Por el tipo de trabajo que realizaban}

- Escribanos de ayuntamiento ${ }^{5}$ : eran los que, siendo vecinos de una ciudad determinada, eran nombrados por el concejo para que prestaran fe pública de los asuntos derivados de su actividad cotidiana (Losa Contreras, 2010, p. 297). Además, solían hacerse cargo de la gestión de la documentación del concejo y de su archivo (Zozaya Montes, 2011, p. 61 y ss.). Se les remuneraba con un salario fijo, al que a veces se añadían dietas o gratificaciones (Cózar Gutiérrez, 2010, p. 284) que generalmente se obtenían de los bienes de propios y los arbitrios del pueblo. Su condición social estaba por encima de la de sus convecinos (en su mayoría campesinos), aunque por debajo de la nobleza; y sus ganancias solían ser asimismo superiores, aunque este aspecto era muy variable, dependiendo de las localidades en las que estuvieran asentados.

- Escribanos de juzgado: eran imprescindibles en el ámbito judicial, pues los procesos se cursaban mediante evidencias escritas certificadas por un escribano, y las sentencias se basaban en lo que estos habían escrito.

- Escribanos del pósito: atendían los actos administrativos del pósito del pueblo.

- Escribanos de la alhóndiga: atendían los actos administrativos de la alhóndiga del pueblo.

- Escribanos públicos: se encargaban de dar fe pública de los asuntos privados de las personas: compras y ventas, testamentos, donaciones, contratos de aparcería, etc. Esta parte del oficio era la que solía reportar mayores ingresos a los escribanos.

- Otros escribanos: el Consejo del Reino nombraba escribanos para ejercer ciertas funciones específicas: eran los escribanos de Millones, de Sacas y Aduanas, etc. Estos cargos ${ }^{6}$ tenían prestigio, autoridad y buenas ganancias, por lo que eran muy codiciados (Guerra Guerra, 1977, p. 11).

Es conveniente advertir que, por motivos económicos, era corriente la acumulación de trabajos, de manera que, por ejemplo, un escribano de ayuntamiento podía atender también el pósito y además ejercer como escribano público.

Una vez considerada brevemente la figura del escribano, pasamos a revisar la fuente que nos ha servido de base en el presente trabajo.

\section{LA FUENTE: EL INTERROGATORIO DE LA REAL AUDIENCIA}

Para realizar esta investigación, nos hemos basado en el análisis del interrogatorio que llevó a cabo la Real Audiencia de Extremadura tras implantarse en dicha provincia en el año $1790^{7}$. Este interrogatorio se integra en la larga tradición española de censos e interpelaciones utilizados por el Estado para ejercer de forma efectiva su autoridad. Porque, como afirma Rodríguez Cancho, el Estado Ilustrado concebía el poder como "un proceso de racionalización y concentración, que produce información, pero también la exige, y que necesita recabar dicha información para ejercer la política que le va a permitir la consecución de sus objetivos" (Rodríguez Cancho, 1993, p. $35)$.

La importancia que se le daba a la información queda de manifiesto en el esfuerzo invertido por los gobernantes españoles para llevar a cabo, a lo largo de la historia, distintos censos e interrogatorios. Haciendo un breve recorrido histórico, podemos citar, por ejemplo, el Censo de Pecheros realizado por Carlos I ${ }^{8}$; las Averiguaciones y el Censo de los millones ordenados por Felipe II; el Vecindario de la Sal, todavía bajo el reinado de los Austrias; el Censo de Campoflorido con Felipe V, ya perteneciente a la dinastía borbónica; y el Catastro de Ensenada, el Censo de Aranda o el Censo de Floridablanca, durante el reinado de Carlos III ${ }^{9}$. 


\begin{tabular}{|c|c|c|c|}
\hline SIGLO & NOMBRE & AÑOS & REY \\
\hline \multirow{4}{*}{ Siglo XVI } & Censo de Pecheros & $1528 / 1558$ & Carlos I \\
\hline & $\begin{array}{l}\text { Relaciones } \\
\text { histórico- } \\
\text { geográfico- } \\
\text { estadísticas de los } \\
\text { pueblos de España } \\
\text { o } \\
\text { "Averiguaciones" }\end{array}$ & $1574 / 1578$ & \multirow[t]{3}{*}{ Felipe II } \\
\hline & $\begin{array}{l}\text { Relaciones } \\
\text { geográficas de } \\
\text { Indias }\end{array}$ & $1577 / 1586$ & \\
\hline & $\begin{array}{l}\text { Censo de Castilla } \\
\text { de } 1591 \text { o "de los } \\
\text { millones" }\end{array}$ & 1591 & \\
\hline \multirow{3}{*}{ Siglo XVII } & $\begin{array}{l}\text { Vecindario de la } \\
\text { Sal }\end{array}$ & 1631 & \multirow[t]{2}{*}{ Felipe IV } \\
\hline & $\begin{array}{l}\text { Vecindario } \\
1646\end{array}$ & 1646 & \\
\hline & $\begin{array}{ll}\text { Vecindario } & \text { de } \\
\text { Milicias } & \end{array}$ & 1693 & Carlos II \\
\hline \multirow{7}{*}{ Siglo XVIII } & $\begin{array}{ll}\text { Vecindario } & \text { de } \\
\text { Campoflorido } & \\
\end{array}$ & $1712 / 1717$ & Felipe V \\
\hline & $\begin{array}{ll}\text { Catastro } & \text { de } \\
\text { Ensenada } & \\
\end{array}$ & $1740 / 1756$ & Fernando VI \\
\hline & Censo de Aranda & 1768 & \multirow{3}{*}{ Carlos III } \\
\hline & $\begin{array}{ll}\text { Encuesta } & \text { de } \\
\text { Tomás López } & \end{array}$ & $1776 / \ldots$ & \\
\hline & $\begin{array}{ll}\text { Censo } & \text { de } \\
\text { Floridablanca } & \end{array}$ & $1786 / 1787$ & \\
\hline & $\begin{array}{l}\text { Interrogatorio de } \\
\text { la Real Audiencia } \\
\text { de Extremadura }\end{array}$ & 1791 & \multirow[t]{2}{*}{ Carlos IV } \\
\hline & Censo de Godoy & 1797 & \\
\hline
\end{tabular}

Si bien muchos de ellos tenían una finalidad recaudatoria, algunos buscaban información más completa, aunando el control administrativo y fiscal con el ideal ilustrado de fomentar el progreso de la nación mediante la realización de reformas desde el poder. Los datos obtenidos (tanto de carácter básico, como son el número de vecinos o habitantes, su estado civil, edad o bienes, como otros más complejos que concernían a aspectos educativos, profesionales, judiciales, religiosos, etc.) proporcionaron los instrumentos necesarios para desplegar la autoridad real desde la capital de la nación hasta las aldeas más remotas. Esto se realizaba fundamentalmente a través de una red de funcionarios que se repartían en todas las instancias del Estado (consejos, intendentes, corregidores, escribanos...).

Siguiendo esta corriente, cuando la nueva audiencia se instaló en Cáceres quiso recopilar información pormenorizada sobre el territorio que iba a estar a su cargo. Como es bien sabido, en la Edad Moderna los tribunales tenían atribuciones muy amplias, que superaban los asuntos judiciales que asumen hoy en día (Lorenzo Cadarso, 1999, p. 205), por lo que la recién creada institución elaboró un interrogatorio de 57 preguntas sobre temas muy variados: administrativos, geográficos, demográficos, educativos, agrícolas, religiosos, etc. ${ }^{10}$ Esta consulta se envió a principios de 1791 a todos y cada uno de los 372 municipios que había en la provincia, con el encargo de ser respondido de forma independiente por las autoridades civiles y religiosas de los mismos ${ }^{11}$.

Con este fin se dividió el territorio extremeño en nueve demarcaciones, que correspondían a los ocho partidos que componían la provincia (Alcántara, Badajoz, Cáceres, La Serena, Llerena, Mérida, Plasencia y Trujillo), más las tierras de la jurisdicción de Coria, que se dividieron a partir de la de Plasencia, formando desde entonces el partido número nueve. Y se nombró a un miembro de la propia audiencia como responsable de cada demarcación (un "visitador"), encargado de realizar el interrogatorio en los municipios de su partido. Con las respuestas obtenidas se elaboró un expediente para cada pueblo, que se depositó en la Escribanía de Acuerdo de la Real Audiencia. Los 
expedientes de todos los pueblos del mismo partido se reunieron en un libro, que se completó con un informe general sobre el territorio elaborado por el visitador correspondiente.

Aunque se aprecian variaciones ${ }^{12}$, en gran parte de las poblaciones el resultado del interrogatorio fue un pliego de respuestas redactado por la Justicia y Ayuntamiento, y otro distinto escrito por la autoridad eclesiástica del lugar. En ocasiones intervenía también un grupo de peritos, que informaba de algún aspecto particular que el visitador asignado considerase de especial importancia. Por último, el propio visitador podía inspeccionar personalmente cada pueblo, observando por sí mismo su estado; además, tenía la posibilidad de entrevistar a las personas que considerase convenientes para recabar más información. Por tanto, la documentación de cada municipio solía incluir las respuestas de la justicia, las aportadas por el párroco y, si existían, los informes complementarios de los peritos y las anotaciones o informes del propio visitador. Todas las precauciones que se tomaron al realizar el interrogatorio dan como resultado un panorama realista y pormenorizado de la vida de los pueblos y ciudades de la provincia de Extremadura a finales del siglo XVIII. Los manuscritos originales se custodian hoy día en el Archivo Histórico Provincial de Cáceres ${ }^{13}$.

En los años 80 y 90 del pasado siglo, esta documentación fue transcrita en su totalidad por un equipo liderado por los profesores de la Universidad de Extremadura Gonzalo Barrientos Alfageme y Miguel Rodríguez Cancho, y editada en 11 extensos volúmenes (Barrientos Alfageme y Rodríguez Cancho, 1993-1996). Esta ingente labor ha facilitado extraordinariamente la realización de investigaciones sobre distintos aspectos de la Edad Moderna en Extremadura, como es el caso del presente artículo.

\section{OBJETIVOS Y METODOLOGÍA}

\subsection{OBJETIVOS}

Con este trabajo nos proponemos dos objetivos principales:

Conocer la situación de los escribanos y de los fieles de fechos en la Extremadura de finales del siglo XVIII, según los documentos del interrogatorio de la Real Audiencia. Para conseguir este propósito, establecemos los siguientes tres objetivos específicos:

- Analizar la presencia y funciones del escribano en la Extremadura de finales del siglo XVIII.

- Examinar los salarios de los escribanos, tratando de concretar sus causas y consecuencias. Esto nos ayudará a vincular la historia de la cultura y la historia económica.

- Conocer los lugares de Extremadura en los que se establecían los escribanos.

Aplicar las técnicas documentales al análisis histórico. Esto supone, por un lado, seleccionar los textos relacionados con los escribanos que existen en el interrogatorio; y, por otro, establecer análisis documentales de carácter formal y de contenido e incorporarlos en un sistema de búsqueda y recuperación que sustenta un sistema de información histórica.

\subsection{RECURSOS METODOLÓGICOS}

Los recursos metodológicos que se han empleado para alcanzar los objetivos propuestos son: la utilización de tecnologías de la información, el uso de técnicas de análisis documental y la realización de un análisis histórico ${ }^{14}$.

a) Tecnologías de la información: hemos diseñado e implementado una base de datos histórica, utilizando el software de gestión de bases de datos documentales Knosys Standalone Professional. Esta base de datos recoge los textos completos que aparecen en el interrogatorio -ya en su versión transcrita, publicada por la Asamblea de Extremadura- referidos a los escribanos, a la administración de las poblaciones y a otros aspectos de interés para esta investigación. Dichos textos proceden de las respuestas que dieron las autoridades civiles y eclesiásticas de cada una de las poblaciones extremeñas a las preguntas 1, 2, 6 y 12 del interrogatorio (a las que haremos referencia más adelante), y de las anotaciones o informes relacionados con el tema elaborados por los visitadores correspondientes. Esta base de datos incluye los siguientes campos, la mayor parte de los cuales son de carácter recuperable:

- Zona: en este campo se consigna el nombre del partido en el que se ubica la población de referencia.

- Población: nombre de la localidad que aporta la respuesta -o respuestas- recogidas en el campo "cita".

- Pregunta: número de la pregunta respondida.

- Fuente: título, número y páginas del volumen en el que se recoge el texto o textos del campo "cita".

- Descriptores temáticos: descriptores temáticos que indizan el contenido recogido en el campo "cita".

- Cita: es el campo al que se refieren todos los demás. En él se incluye el texto completo de las respuestas a la pregunta que se indica en el campo "pregunta", por parte de las autoridades -civiles y eclesiásticas- del 
pueblo concreto del que se trate; También se recogen aquí los comentarios o notas elaborados por el visitador del pueblo acerca del tema.

- Observaciones: destinado a consignar información adicional de interés.

Además, se ha elaborado otra base de datos complementaria, de menor entidad, que sirve para saber el número de vecinos de cada localidad. Está basada únicamente en las respuestas que se dan a la pregunta $\mathrm{n}^{\mathbf{0}} 3$, que se refiere precisamente al número de vecinos de la localidad interrogada. Esta base de datos incluye cuatro campos:

- Población: nombre de la población de referencia.

- Zona: partido al que pertenece la población.

- Vecinos: número de vecinos del pueblo. Dicho brevemente, se refiere al número de hogares o casas familiares que había en la localidad.

- Habitantes: conversión del número de vecinos a la cantidad aproximada de habitantes, utilizando un coeficiente de 4 habitantes por vecino ${ }^{15}$.

- Auxiliar: campo adicional para consignar datos de utilidad que no se hayan podido incluir en los demás campos.

b) Técnicas de análisis documental: se ha realizado una lista de descriptores temáticos controlados, integrada en la base de datos principal a la que hemos hecho referencia. Mediante estos descriptores hemos representado el contenido de los textos recogidos en el campo "cita" de cada registro. Esto ha permitido la posterior realización de búsquedas temáticas (utilizando para ello operadores booleanos) con objeto de recuperar la información necesaria a medida que avanzaba nuestra investigación. El resultado de estas búsquedas ha sido un conjunto de datos que hemos tratado mediante el programa Excel, elaborando con ellos las tablas y gráficos que han sido precisos.

c) Análisis histórico: la información obtenida y tratada ha sido sometida a análisis histórico. Para ello se han utilizado métodos cuantitativos (cuando ha sido posible) y métodos cualitativos, cuando los cuantitativos no se podían usar o lo hayamos considerado más adecuado para nuestra investigación.

\subsection{SELECCIÓN DE LOS TEXTOS SOBRE ESCRIBANOS EN EL INTERROGATORIO}

Como inicio del proceso, se ha explorado el interrogatorio de la Audiencia en su versión publicada para averiguar qué preguntas hacían referencia directa a los escribanos. Estas preguntas son la $\mathrm{n}^{\mathrm{o}} 2 \mathrm{y}$ la $\mathrm{n}^{\circ} 6$. Posteriormente, hemos extraído las respuestas dadas a las mismas por las autoridades civiles y por las religiosas de cada población de Extremadura, a lo que hemos añadido - cuando existen- los informes o notas sobre el tema aportados por los visitadores de los pueblos. Dichos textos han sido escaneados e incluidos en el campo "cita" de la base de datos principal descrita más arriba, y han servido de base para la elaboración de cada registro de la misma. Estas, pues, son las principales fuentes documentales en las que se basa el presente estudio ${ }^{16}$.

Recogemos a continuación información sobre ambas preguntas:

- Pregunta $n^{\circ}$ 2: es una cuestión extensa, que pide información sobre varios temas relacionados con la administración municipal; entre ellos, se refiere expresamente a distintos aspectos relacionados con los escribanos de la población, como se puede comprobar en el fragmento que reseñamos a continuación: "[...] qué número hay de Abogados, de Procuradores y Escribanos, y si son Reales ó Numerarios; si con respecto al vecindario sobran ó faltan, y el número de todos los subalternos, expresando su salario, si le tienen, y qué arancel se observa en los juzgados "17.

- Pregunta $\mathrm{n}^{\circ}$ 6: se refiere a la conservación y custodia de los protocolos de los escribanos. En ella se resaltan los perjuicios causados por el descuido de dichos protocolos y la necesidad de su custodia ${ }^{18}$ : "Como han sido muy graves é irreparables los perjuicios que algunas veces ha ocasionado el abandono de los protocolos, y oficios públicos por muerte de los Escribanos Reales y Actuarios, se tomará conocimiento en cada Pueblo del destino, que se les haya dado, y si están con el resguardo, y seguridad conveniente para evitar su extravio".

El examen detenido de las respuestas a estas preguntas aporta una información fundamental para conocer la situación de los escribanos en la región. Pero, además, en el interrogatorio existen otras cuestiones de carácter transversal que resultan imprescindibles para realizar esta investigación, como son las que hacen referencia a:

- La categoría administrativa de cada población que se interrogaba, que aparece en la pregunta no 1: "En la descripcion de cada Pueblo se manifestara si es Ciudad, Villa, ó Aldea, y si es Cabeza de Partido, ó lo que dista de ella, su situacion por los quatro vientos, la distancia á la Villa de Cáceres, la extension de sus términos, con qué Pueblos confina, la distancia de éstos, si son del territorio de la Audiencia, ó de alguna de 
las dos Chancillerías, manifestando en este caso lo que distan de éstas y de aquella, ó de la Audiencia de Sevilla, ó si pertenecen al Reyno de Portugal; teniendo mucho cuidado de especificar los limites del territorio asignado á la Audiencia, y la Diócesis á que corresponden, ó si fuesen nullius”.

- Los recursos económicos con los que contaban, en pregunta n' 12: "Si hay proprios, ó arbitrios, en qué consisten, su valor anual, ó por quinquenio, y si hay otros caudales públicos, que no estén comprehendidos en aquellos ramos, su destino, e inversión".

Las respuestas a estas cuestiones se han incluido en la base de datos principal.

Por otra parte:

- El número de vecinos de los municipios, en la pregunta no 3: "Qué vecindario tiene cada Pueblo, su aplicación y oficios, el número de cada clase: si forman Gremio con ordenanzas aprobadas, ó no: si hacen exámenes para el ingreso, y su cósto: qué diversiones suelen ser las mas comunes entre los naturales, ó si se nota inclinacion á algun vicio: si en los oficiales, ó jornaleros se advierte abuso en el modo, ú horas del trabajo, y el precio corriente de los jornales".

Las respuestas a esta cuestión se han incluido en la base de datos adicional sobre los "vecinos".

Finalmente, también hemos tenido en cuenta otros aspectos que podían aportar información adicional, como la redacción de las respuestas, escritas por los propios escribanos o, en su ausencia, por los fieles de fechos de las poblaciones interrogadas.

\section{ANÁLISIS Y RESULTADOS}

Así pues, el escribano era necesario para realizar distintas labores relacionadas con documentos: gestionar la documentación y el archivo municipales, formalizar los actos llevados a cabo entre particulares y custodiar la documentación resultante, actuar en los juzgados, etc. Además, podía leer los escritos oficiales que llegaban al ayuntamiento, interpretarlos y darles correcta respuesta, así como conocer los privilegios y deberes de su localidad. En consecuencia, su presencia en el concejo se consideraba imprescindible, y de alguna forma debía garantizar la tranquilidad de las autoridades y de los habitantes de una población en los aspectos que le competían.

\subsection{Distribución de los escribanos en las poblaciones de Extremadura}

Por las razones que hemos expuesto, su presencia era muy común en los municipios extremeños. En el gráfico siguiente $^{19}$ vemos la proporción de poblaciones de cada partido de Extremadura que disponían de, al menos, un escribano $^{20}$ :

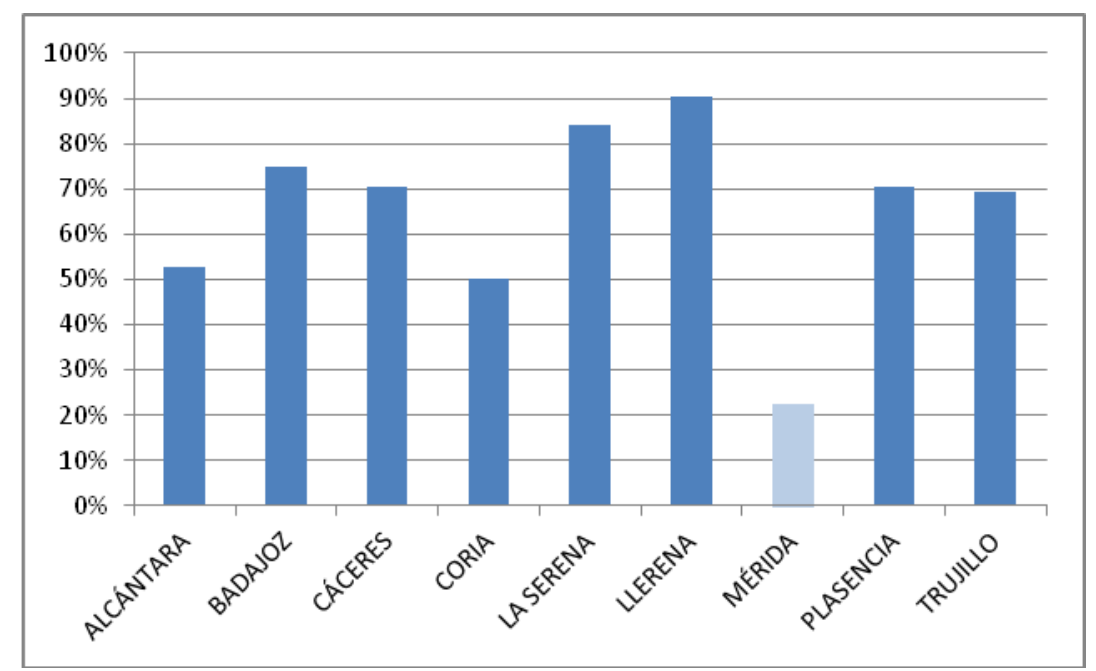

Figura 1. Poblaciones con escribanos (por partidos, en \%).

Como se puede observar, esta proporción, era alta en la mayoría de los partidos (excepto en el de Mérida que, como se ha indicado en nota, no podemos tener en cuenta debido a la destrucción de la mayor parte de su documentación). No obstante, se aprecian diferencias significativas entre ellos: destacan los de Llerena (con escribano en el 90\% de los pueblos) y La Serena (en el 84\%), seguidos de Badajoz (75\%) y Cáceres, Plasencia y Trujillo (donde rondan el 70\%); mientras que en los partidos de Alcántara y Coria solo encontramos escribano en aproximadamente el 
$50 \%$ de las localidades. Así pues, aunque constatamos la existencia de esta figura en una gran parte de las poblaciones de Extremadura, también es significativo el número de núcleos que carecía de ella, sobre todo en los dos partidos señalados.

Estas diferencias territoriales pueden explicarse, en algunos casos, por una combinación de factores económicos, administrativos y demográficos ${ }^{21}$. Incluimos a continuación gráficos que representan dos de estos factores: el promedio de caudales de propios y el de vecinos, por partidos.

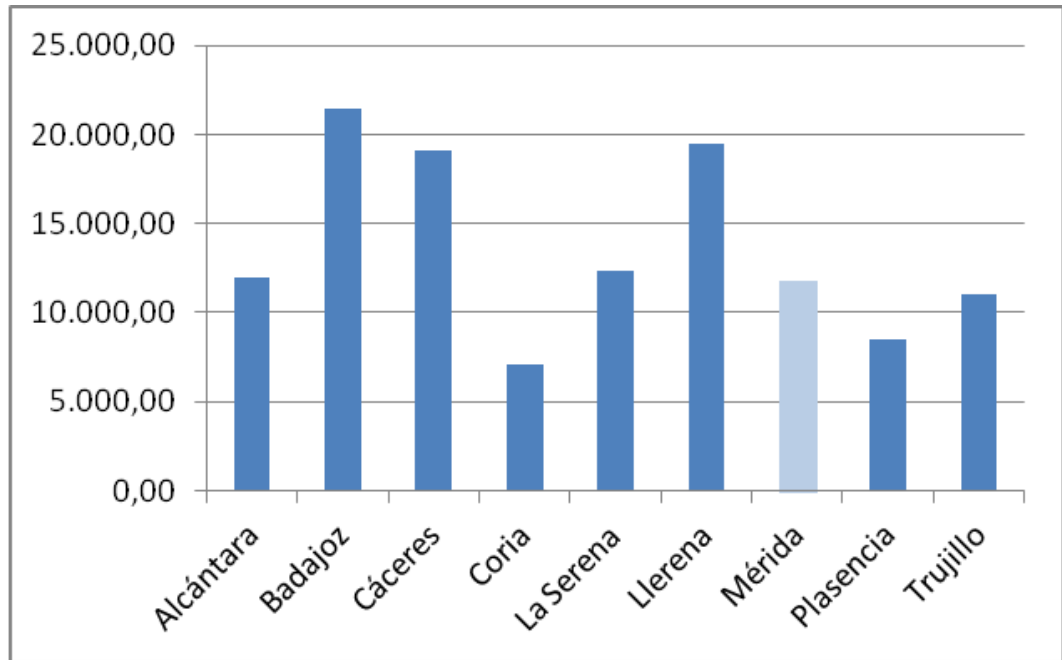

Figura 2. Caudales de propios (promedio en cada partido).

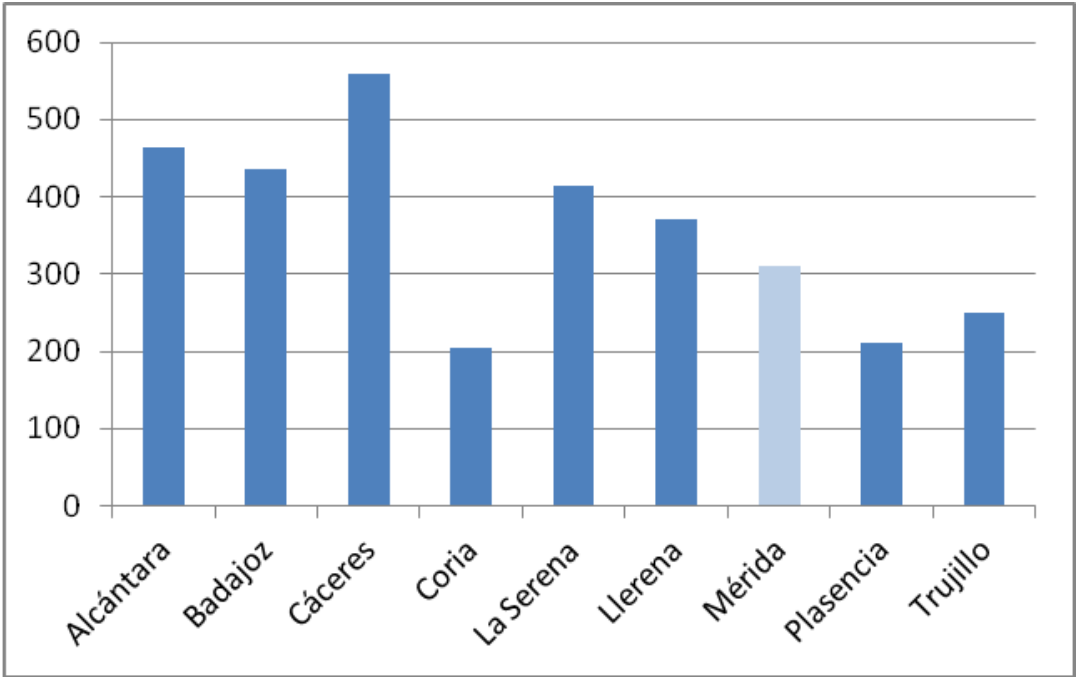

Figura 3. Número de vecinos (promedio en cada partido).

Por ejemplo, Llerena (el territorio en el que más pueblos disponían de escribano) ocupaba un terreno de dehesas y fértiles campiñas aptas para cultivo. Su capital fue durante años sede de los maestres de la Orden de Santiago, y bajo la jurisdicción de esta orden estaban, en la época del interrogatorio, el $49 \%$ de las poblaciones, mientras que el 39\% eran de realengo y solo un $12 \%$ de señorío. En la ciudad de Llerena se ubicaba el tribunal de la Inquisición, cuya actividad administrativa y judicial debió repercutir positivamente en la presencia de escribanos en su zona de influencia. Estos factores, junto con la relativa riqueza de los propios del partido y el predominio del villazgo en sus poblaciones (el 95\% tenían categoría de villas), pueden justificar su alto índice de escribanos.

En cuanto al partido de Badajoz, probablemente fue decisiva la existencia de dos ciudades ${ }^{22}$; una de ellas, Badajoz, era la más populosa de la provincia, y su actividad militar, religiosa y administrativa pudo redundar en los pueblos de la zona. Por otra parte, era una región fronteriza con Portugal, en la ruta de Madrid hacia Lisboa, y dotada de terrenos llanos y productivos. El promedio de caudales de propios del partido era el más alto de Extremadura, y el de vecinos 
también de los mayores. Dichas circunstancias, que exponemos de forma muy resumida, explican la presencia de escribanos en la mayor parte de sus poblaciones.

En cuanto a los partidos con el número más bajo de pueblos con escribano, encontramos que en Alcántara, si bien predominaba el villazgo y el promedio de vecinos era relativamente elevado, no existía ninguna ciudad o gran núcleo de población -con la actividad administrativa, comercial, etc. que estos conllevaban- y los propios eran escasos. Estas condiciones pueden fundamentar el relativamente bajo porcentaje de municipios con escribano (52\%), si bien dicha circunstancia se compensaba con la presencia de fieles de fechos -cuyos sueldos eran mucho más bajos- en el $42 \%$ de los municipios, como veremos más adelante.

Por último, en Coria, que se encuentra en último lugar (50\% de poblaciones con escribano), se unen varios factores: era un territorio con cierto grado de aislamiento geográfico, próximo a las sierras de Gata y de Béjar, y alejado de las zonas más pobladas de la provincia. Había una ciudad -Coria- que era la capital de partido, pero la mayor parte de sus poblaciones tenían la categoría de aldeas (el 85\%), generalmente con escaso número de vecinos. Este tipo de localidad dependía administrativa y jurídicamente, en gran medida, de otra población mayor, lo que quizás explica la escasa presencia de escribanos. Además, era el partido más pobre de la provincia en lo que a caudales de propios se refiere. Como era habitual, también en este territorio se compensaba la ausencia de escribano con la contratación de un fiel de fechos en el concejo.

Más difícil de explicar es el alto porcentaje de pueblos con escribano en otros partidos, como La Serena (84\%), un territorio relativamente reducido que en su totalidad pertenecía jurisdiccionalmente a la orden de Alcántara. No existía ninguna ciudad ni núcleo de población especialmente populoso, si bien la práctica totalidad de sus municipios tenían categoría de villa (el 95\%). Además, se encontraba en la media de la provincia tanto en promedio de vecinos como de caudales de propios.

En cualquier caso, como la presencia de un escribano era imprescindible para proporcionar carácter legal a ciertos actos, las autoridades de los municipios que carecían del mismo se veían en la necesidad de buscar soluciones sin tener que hacer un gran desembolso. Los arreglos más frecuentes eran:

- Recurrir a escribanos de otros pueblos cercanos. Esto se hacía de dos formas: bien estableciendo una especie de acuerdo con ellos y pagando por su asistencia regular una determinada cantidad de dinero al año, como sucedía en Santa Marta (partido de Trujillo), donde se dice: "No hay procuradores ni abogados ni notarios, el escribano de La Cumbre la asiste, le dan doscientos reales del fondo de propios"23. O bien llamando al escribano de un municipio vecino de forma puntual, si era necesaria su presencia. De esta manera sucede, por ejemplo, en Fuente del Arco (Llerena), donde normalmente solo había un fiel de fechos: "Si ocurre alguna escritura puede venir el [escribano] de Llerena que está a corta distancia ${ }^{, 24}$.

- Compartir un mismo escribano entre dos pueblos: en este caso, una escribanía se compartía entre dos municipios, y el escribano servía oficialmente en los concejos de ambas localidades. De esta forma, el desembolso realizado por los ayuntamientos resultaba más asequible, y el escribano conseguía reunir mejor salario. Así ocurre, por ejemplo, en Santa Ana y Ruanes (del partido de Trujillo), que compartían la misma escribanía, cada uno pagando su parte al escribano ${ }^{25}$ : "Hay [...] solo un escribano del numero y ayuntamiento, que sirve también a la villa de Santa Ana por estar unido el oficio” (Ruanes). El partido en el que más se utilizaba este recurso era Plasencia.

- Nombrar a un fiel de fechos: como ya hemos dicho, era una medida frecuente. El fiel sustituía al escribano en sus funciones habituales, aunque los documentos que redactaba no podían tener la validez legal que aquél les confería. Solía ser nombrado por el ayuntamiento, que escogía, de entre los hombres del pueblo, a uno honrado que supiera leer y escribir más o menos correctamente. En algunos núcleos coexistían fiel y escribano: este último se dedicaba a "lo público" o/y el juzgado (es decir, a las cuestiones de los particulares, que eran quienes le remuneraban), mientras que el fiel de fechos atendía al ayuntamiento, que de esta forma solucionaba sus necesidades pagando un salario menor ${ }^{26}$. También se dan casos, como en Puebla de Sancho Pérez (Llerena), en los que un fiel sustituye al escribano por estar este enfermo: "Que hay solo un escribano, que lo es por autorización de dicho Consejo y por estar achacoso suele servir un fiel de fechos".

En el gráfico siguiente se aprecia el porcentaje de poblaciones de cada partido que tenían escribano y el de aquellas que tenían fiel de fechos: 


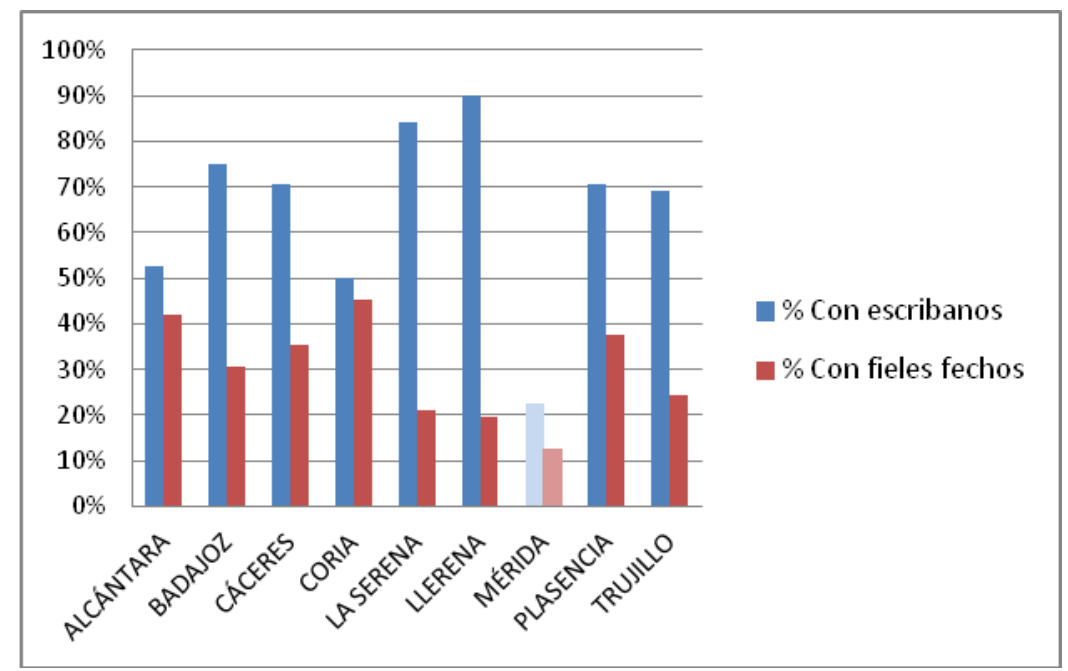

Figura 4. Poblaciones con escribanos y con fieles de fechos (por partidos, en \%).

Aunque en todos los partidos destaca claramente la proporción de escribanos, la de fieles de fechos también resulta relevante. Como es natural, el número de estos últimos es inversamente proporcional al de escribanos, de forma que son los partidos de Coria y Alcántara los que mayor porcentaje tienen, así como Llerena y La Serena el menor. En todo caso, se constata que muy pocos pueblos de la provincia de Extremadura carecían de uno u otro, lo que nos muestra la importancia que tenía la labor de estos funcionarios en la sociedad.

Una vez revisada la existencia de escribanos en la provincia de Extremadura, vamos a analizar sus distintas clases, según se nombran en las respuestas al interrogatorio.

\subsection{Tipos de escribanos en la provincia}

Como precisamos con anterioridad, los escribanos pueden clasificarse según dos criterios diferentes: por la zona en la que podían ejercer su oficio, y por el trabajo que desempeñaban.

\subsubsection{Tipos de escribanos por la zona en la que podían ejercer su oficio}

Recordemos que, dentro de los tipos de escribanos según la zona en la que ejercían su profesión, encontramos a los escribanos del número, los reales y los de las órdenes. El gráfico siguiente representa el número de escribanos que había en Extremadura, clasificados según este criterio:

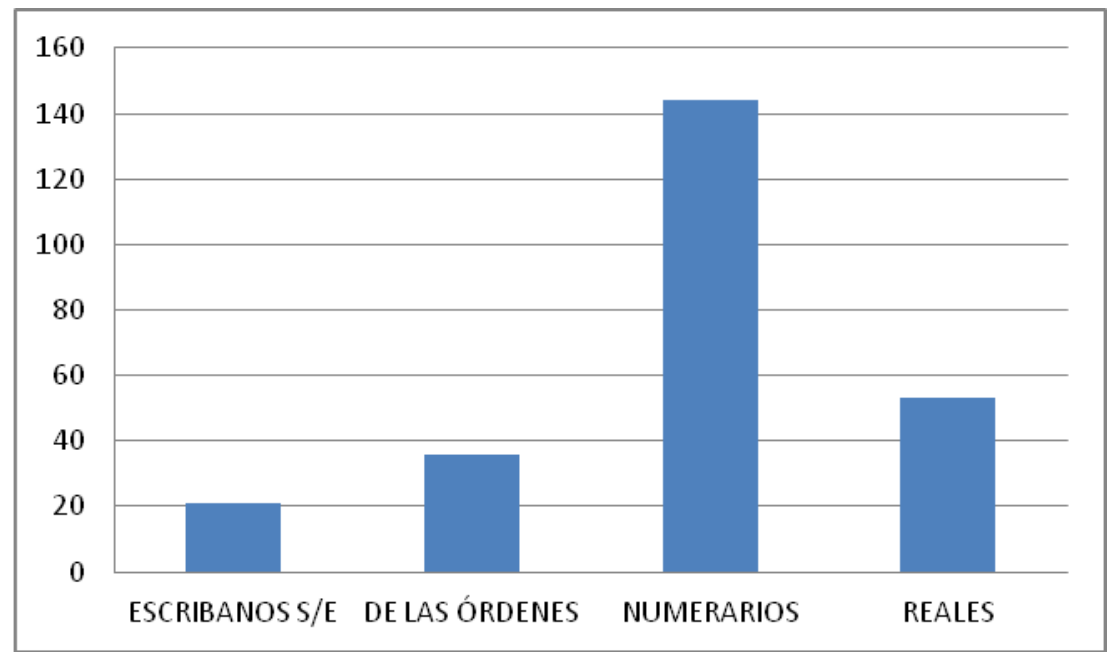

Figura 5. Número de escribanos según el territorio en el que podían trabajar.

Se aprecia claramente que los más numerosos eran los escribanos numerarios, que suman más de 140 y suponían, en términos relativos, el $56 \%$ del total. Esta prevalencia resulta normal, dado que cada población establecía el número de escribanos que veía necesario, generalmente basándose en su número de vecinos y en sus posibilidades económicas; así, con frecuencia encontramos núcleos con varios escribanos (como Badajoz, Jerez de los Caballeros, 
Brozas, Cáceres, etc.). En segundo lugar, aunque con gran diferencia, aparecen los escribanos de los reinos o reales (53 escribanos, el $22 \%$ ), y después los escribanos de las órdenes (un total de 36, el 15\%). Este número ${ }^{27}$ no es despreciable, y se debe a la presencia que las órdenes de Santiago y Alcántara habían tenido durante siglos en el territorio de Extremadura. Aunque a finales del siglo XVIII el territorio bajo su jurisdicción había disminuido, seguían muy presentes, sobre todo en los partidos de Alcántara, La Serena, Llerena y Mérida. Por último, hemos encontrado, un cierto número de respuestas (21) que no especifican el tipo de escribano que había en una población, y que representamos con las siglas $\mathrm{S} / \mathrm{E}$ (sin identificar).

Por otra parte, en numerosos pliegos de respuestas se afirma que no se necesitan más escribanos en la localidad, y que basta con el -o los- que había en ese momento para solventar sus necesidades; incluso se dice, en ocasiones, que había más de los que eran necesarios. Generalmente, eran los visitadores los que hacían referencia a este exceso; así sucede, por ejemplo, en la ciudad de Plasencia, donde había 11 escribanos en activo, más una escribanía vacante. El visitador informa de que el número es "excesivo, intolerable, perjudicial" para un municipio de 1.100 vecinos $^{28}$. Esta situación se daba de forma similar en toda la nación desde el siglo XVII, como consecuencia de la política real de crear nuevas escribanías para obtener dinero (Extremera Extremera, 2001, p. 164). Esta política tuvo consecuencias negativas para la profesión y para el pueblo en general, pues finalmente las escribanías solo podían ser adquiridas por personas con dinero que querían recuperar cuanto antes la inversión realizada, cayendo a veces en el abuso e incluso en la ilegalidad al realizar sus funciones. Además, al tener que repartir la clientela entre varios, los escribanos obtenían menos beneficios económicos; esto puede explicar - al menos en parte- los abusos e ilegalidades a los que recurrían algunos para obtener mayores ganancias ${ }^{29}$.

Por el contrario, las poblaciones que no tenían escribano manifestaban su necesidad de él, como sucede en Villasbuenas de Gata (Alcántara), donde "consideran hace falta mui considerable uno [escribano] aprobado para asistir al juzgado y aiuntamiento",30. También encontramos algunos municipios (pocos) que indican que es necesario aumentar su número, como Jaraicejo (Trujillo), cuya respuesta dice: "Por no contemplar suficiente un escribano para el vecindario, ai echo recurso al Consejo para aumento de otro como anteriormente le a habido" 31 .

\subsubsection{Tipos de escribanos por el trabajo que desempeñaban}

Los escribanos podían trabajar en la corte, en las chancillerías y audiencias, ayuntamientos, rentas públicas, pósitos, alhóndigas, juzgados, atendiendo a los asuntos de particulares o sirviendo de administradores de algún noble. Según las respuestas al interrogatorio de la Real Audiencia, en Extremadura el número de escribanos de los distintos tipos era el siguiente:

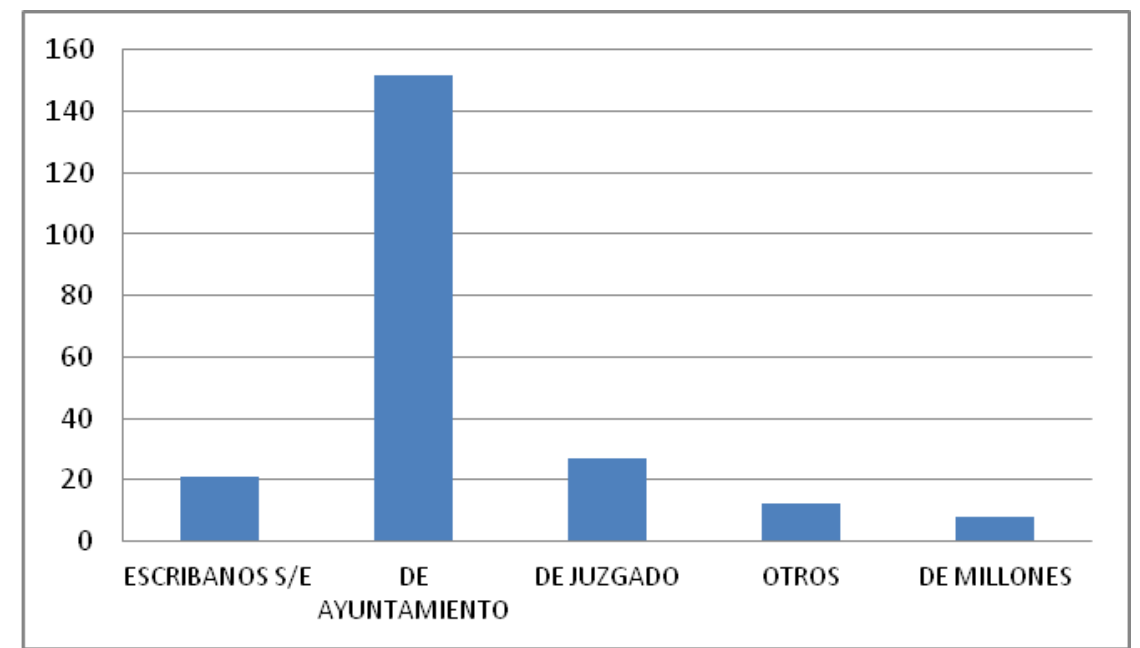

Figura 6. Número de escribanos según el trabajo que desempeñaban.

Siguiendo este criterio, destacan muy por encima de los demás los escribanos "de ayuntamiento", es decir, los que atendían los asuntos de dicha institución en las poblaciones extremeñas, realizando las funciones que eran necesarias: redactar los libros de contenido municipal (como los de actas de las sesiones del ayuntamiento), acompañar a los regidores y oficiales del concejo en las comisiones para dar fe de lo que sucedía en ellas, asistir a los pleitos promovidos por la villa, hacerse cargo de una de las llaves de su archivo y gestionarlo, dar fe pública de la elección de cargos locales, etc. (Villalba Pérez, 2002, p. 128). 
En las respuestas a la pregunta $\mathrm{n}^{\mathbf{0}} 2$, en las que nos basamos para analizar este punto, no se suele hacer referencia detallada a estas funciones. Sin embargo, a veces se hacen algunas indicaciones; por ejemplo, en Benquerencia (Partido de Mérida), se dice:

"Enseguida se nombra por su ayuntamiento a el escribano de ayuntamiento [...] para que asista a él, despache las órdenes del real servicio y formalize quanto ocurra al beneficio del pueblo, lo que se a hecho consultivo al Real Consejo de Castilla por no constar en dicho reglamento salario alguno y no poder pasar sin el”.

Y el párroco de Casas de Don Pedro (partido de Trujillo), alude al "escribano numerario de ayuntamiento, a cuio cargo corren también todos los acuerdos y negocios del cabildo".

Como los ayuntamientos eran organismos administrativos presentes en la práctica totalidad de las poblaciones, los escribanos a su servicio son los que con más frecuencia se mencionan en las respuestas. Solían ser nombrados por los propios concejos, que los elegían de entre los avecindados en la población. Sin embargo, se dan casos en los que, para ahorrar en el salario, se contrataba a un fiel de fechos aunque hubiese escribanos disponibles en la localidad ${ }^{32}$. En las zonas de señorío, a veces era el señor jurisdiccional el que tenía el privilegio de nombrar al escribano de un ayuntamiento $^{33} ; \mathrm{y}$, de forma excepcional, el Monasterio de Guadalupe tenía el privilegio de nombrar escribanos, por ejemplo, en la misma ciudad de Trujillo.

Como muestra el gráfico, también aparecen en las respuestas -si bien en menor número- otros tipos de escribanos, como los de juzgado, los de millones, y los que hemos denominado "Otros" por su escaso número, donde se incluyen conjuntamente los del pósito, alhóndiga, rentas, etc. Por último, algunas poblaciones no especifican la dedicación de sus escribanos.

Es importante recordar que, con frecuencia, el mismo escribano desempeñaba dos o más de estos oficios en la localidad $^{34}$. En muchos casos actuaba además como "escribano público", es decir, atendía a los particulares, lo que le proporcionaba la mayor parte de sus ingresos. Es bastante usual encontrar en las respuestas la afirmación de que un escribano era "público y de ayuntamiento", o "de lo público y juzgado" en los pueblos extremeños 35 .

\subsection{Problemas relacionados con los escribanos encontrados en el interrogatorio}

La documentación analizada muestra la existencia de algunos problemas relacionados con los escribanos, que señalamos a continuación.

\subsubsection{Concepto patrimonial de la documentación}

Según hemos visto, los escribanos de ayuntamiento actuaban con frecuencia como escribanos públicos. Como en el concejo eran los que atendían de manera casi exclusiva la documentación y el archivo municipales, al cabo de los años algunos llegaban a considerar dicha documentación como propia, más aún en los casos en los que, por seguridad, la guardaban en su escribanía particular. En consecuencia, cuando fallecía el escribano, sus herederos se hacían cargo de todos sus documentos, incluyendo los públicos, creyéndose incluso con derecho a venderlos. Así, en la respuesta de Alburquerque (Badajoz) a la pregunta $n^{\circ} 6$ se dice:

"El destino que se ha dado a los protocolos y papeles de los oficios de escrivanos reales y numerarios ha sido mui vario y sin precaucion ni resguardo, a causa de haverse ajudicado los papeles a los herederos o heredero

del escribano difunto, por lo que se hallan dispersos, sin método ni colocación alguno en poder de los particulares que los han adquirido, ya por titulo de compra o herencia..."36.

Otras poblaciones que se refieren a casos parecidos son, por ejemplo, Badillo (Plasencia), donde la Justicia no puede acceder a las ordenanzas del pueblo por estar en manos de los herederos del antiguo escribano; o Fuentes de León (Llerena), donde el visitador encargado del interrogatorio del partido tiene que mandar recuperar los papeles que están en casa del escribano para llevarlos al archivo público; etc.

En ocasiones, cuando un escribano se trasladaba a otra localidad, se llevaba consigo los protocolos elaborados en la población de origen. Al fallecer formaban parte de su herencia, con los problemas que esto podía conllevar.

\subsubsection{Pérdida de documentación}

Cuando un pueblo carecía de escribano propio, el concejo o los habitantes de un pueblo se veían obligados a recurrir a los de pueblos cercanos. Esto podía acarrear problemas como la pérdida de documentación, pues estos escribanos terminaban llevándose los documentos a sus escribanías -ubicadas en sus lugares de origen- de forma que 
quedaban lejos de las personas interesadas y, con el paso del tiempo, acababan extraviándose. Así lo manifestaba el párroco de la población de Mata (partido de Alcántara) en su respuesta:

“... no ai escribano publico y sí fuera muy útil a estos naturales el que hubiese un escribano que tuviese la escribanía de pósito, la pública y de aiuntamiento para su mejor subsistencia, y oi lo que sucede que tienen un fiel de fechos y para quanto se ofrece se nezesita traer un escribano público, que esto es muy costoso y acaso padecer los instrumentos extrabio por salir del pueblo a hazerlos...”.

\subsubsection{Malas prácticas de los escribanos}

Por tener conocimientos superiores a la mayoría de la población, por su carácter de intermediarios con la administración y por sus contactos con los poderosos, los escribanos eran, a veces, objeto de desconfianza por parte de sus conciudadanos.

En efecto, el trámite de asuntos públicos y privados les daba la posibilidad de utilizar su trabajo y la información a la que accedían en su propio beneficio, llegando a realizar actos ilícitos que contrastaban con la exigencia de honestidad $^{37}$ que se requería para acceder al oficio (Cózar Gutiérrez, 2010, p. 273). Esto sucedía especialmente en el ámbito judicial; por ejemplo, algunos escribanos originaban y fomentaban pleitos por los ingresos económicos que les reportaban (Marchant Rivera, 2006, p. 329); o, a cambio de dinero, falseaban la información que debían recabar para los juicios, de forma que un culpable resultaba absuelto (Marchant Rivera, 2006, p. 330) ${ }^{38}$. También cometían delitos en el ámbito de su ejercicio como escribanos públicos, como la falsificación de documentos y firmas, la ocultación malintencionada de registros, el cobro de excesivos derechos ${ }^{39}$, etc. Para evitar estas situaciones, el rey instaba a justicias y corregidores a que supervisaran los actos de los escribanos (Extremera Extremera, 2004, p. 191) ${ }^{40}$; pero era una medida poco eficaz, pues a veces estos contaban con la connivencia de sus superiores (Alejandre García, 1972). Estos actos, como es natural, se consideraban delictivos y estaban penados con duras sanciones, que en el siglo XVIII consistían esencialmente en penas de cárcel, multas y privación de ejercer el oficio (Extremera Extremera, 2004, p. 191).

De la misma forma, en las respuestas al interrogatorio de la Audiencia no es extraño encontrar referencias más o menos explícitas a malas prácticas llevadas a cabo por algunos escribanos. Dichas alusiones suelen ser hechas por los párrocos o los visitadores del partido, y nunca por las autoridades municipales. Esto puede explicarse, por una parte, porque el escribano formaba parte del ayuntamiento y posiblemente tuviera la complicidad de sus superiores; y por otra, porque era el propio escribano quien solía redactar el pliego de respuestas de las justicias, por lo que se cuidaba mucho de escribir algo contrario a sus intereses.

Una de las alusiones que encontramos en el interrogatorio acerca de esta situación es la que hace el visitador de Hinojosa del Valle (partido de Llerena) en una nota sobre la pregunta $\mathrm{n}^{\circ} 5$ :

"El archivo de este pueblo ha estado enteramente abandonado, no se hallan los papeles que corresponden a los años desde 1776 hasta 86 y faltan también otros desde dicho tiempo; tampoco existen los privilegios y se dice constantemente que 30 años hace fue robado el archivo, [...], de modo que todos se han apoderado del archivo de sus papeles, de las cuentas de propios y de todos los documentos con que pudieran contextarse las malas versaciones (sic), las injusticias que han sucedido y las estafas de los escribanos y fieles de fechos".

Otro ejemplo es la crítica del visitador de Arroyomolinos de la Vera (partido de Plasencia), cuando habla en su informe de "...la libertad y la desenvoltura del escribano, que domina en el pueblo casi despóticamente y es el árbitro de los negocios y caudales públicos...”. Lo que contrasta con la información que proporcionan las autoridades del pueblo sobre este funcionario (probablemente redactada por él mismo), que no solo omite cualquier matiz negativo, sino que más bien lo presenta como infortunado por su exiguo sueldo: "Solamente hay un escribano del número y ayuntamiento de este pueblo, que con respecto al vecindario solamente es preciso y bastante el referido escribano del número y ayuntamiento, el que solamente goza el salario anual de novecientos reales".

Finalmente, y como curiosidad, incluimos una cita de las autoridades de Fuente del Arco (Llerena). El pueblo disponía de una escribanía que estaba vacante, y acerca de este asunto se dice: "No parece preciso que haya escribano, pues sin él logra el pueblo bastante tranquilidad”.

Por otra parte, en los pliegos de respuestas de los párrocos y en los informes de los visitadores de varias poblaciones, encontramos testimonios de corrupción de otros cargos públicos ${ }^{41}$, lo que indica que las malas prácticas no eran exclusivas de los escribanos, sino que con frecuencia se insertaban en una administración local corrupta. Como el escribano era una presencia constante en los actos del ayuntamiento, era difícil que dichos abusos tuvieran 
lugar sin su connivencia; quizás esta sea la prueba más importante de las malas prácticas de los escribanos en el desarrollo de su profesión.

Otra cuestión de interés acerca de los escribanos -en parte relacionada con las malas prácticas, pues estas tenían como fin principal obtener mayores ganancias-, es el salario que cobraban por realizar sus funciones. Así lo sugiere el visitador de Campillo (partido de Llerena) en su informe sobre la localidad: "El único escribano de esta villa tiene un tenue salario de propios que consiste en 400 reales, dotación escasa y que no puede servir de premio ni estímulo para obrar fielmente, y combendría su aumento". Así pues, el visitador era consciente de que, con salarios tan bajos, no se podía garantizar la honradez del escribano.

\subsection{Salarios de los escribanos de ayuntamiento}

El escribano que trabajaba en el ayuntamiento de una localidad recibía un salario por parte del propio concejo; si además actuaba como escribano público, obtenía una remuneración adicional de las personas a quienes prestaba servicio, de acuerdo con unos aranceles legalmente establecidos ${ }^{42}$. Gracias a que la cuestión $\mathrm{n}^{\mathrm{o}} 2$ del interrogatorio pregunta expresamente por el salario de los trabajadores del ayuntamiento, tenemos información exacta de las cantidades que cobraban los escribanos o fieles de fechos por su trabajo en una gran cantidad de poblaciones (aunque no en todas), lo que permite analizar este aspecto con detalle.

El dinero para pagar dicho salario se obtenía, en la práctica totalidad de los casos, de los bienes de propios y de los arbitrios de los municipios, que servían para sufragar cualquier gasto público. El valor de los propios era, pues, un factor importantísimo para que se contratase a un escribano, a un fiel de fechos, o, si no eran suficientes, no se contratase a nadie ${ }^{43}$.

Para comprobar si los bienes públicos influían en la cuantía de los salarios, hemos elaborado una serie de tablas correspondientes a cada uno de los nueve partidos extremeños. En ellas se incluye la cantidad obtenida de los bienes de propios y el importe de la paga que cobraban los escribanos de cada municipio ${ }^{44}$. A partir de estas tablas hemos realizado los gráficos correspondientes, con objeto de ver más claramente los resultados ${ }^{45}$. De la misma forma hemos actuado en relación con los fieles de fechos. Como incluir todos aquí sería largo y tedioso, hemos seleccionado, a modo de ejemplo, el gráfico correspondiente al partido de Badajoz. Hemos de señalar que, tanto en este gráfico como en las tablas siguientes, se tienen en cuenta solamente los datos de aquellas poblaciones de las que conocemos propios y salarios, pues el objetivo principal es conocer la relación entre unos y otros.

Por tanto, analizamos el gráfico del partido de Badajoz para comprobar si existe relación entre la cuantía del salario de los escribanos y los caudales de propios de cada pueblo. Se ha de tener en cuenta que hay dos ejes con valores diferentes: el izquierdo corresponde al dinero obtenido de los propios, y el derecho a las cantidades pagadas a los escribanos, ambos en reales al año.

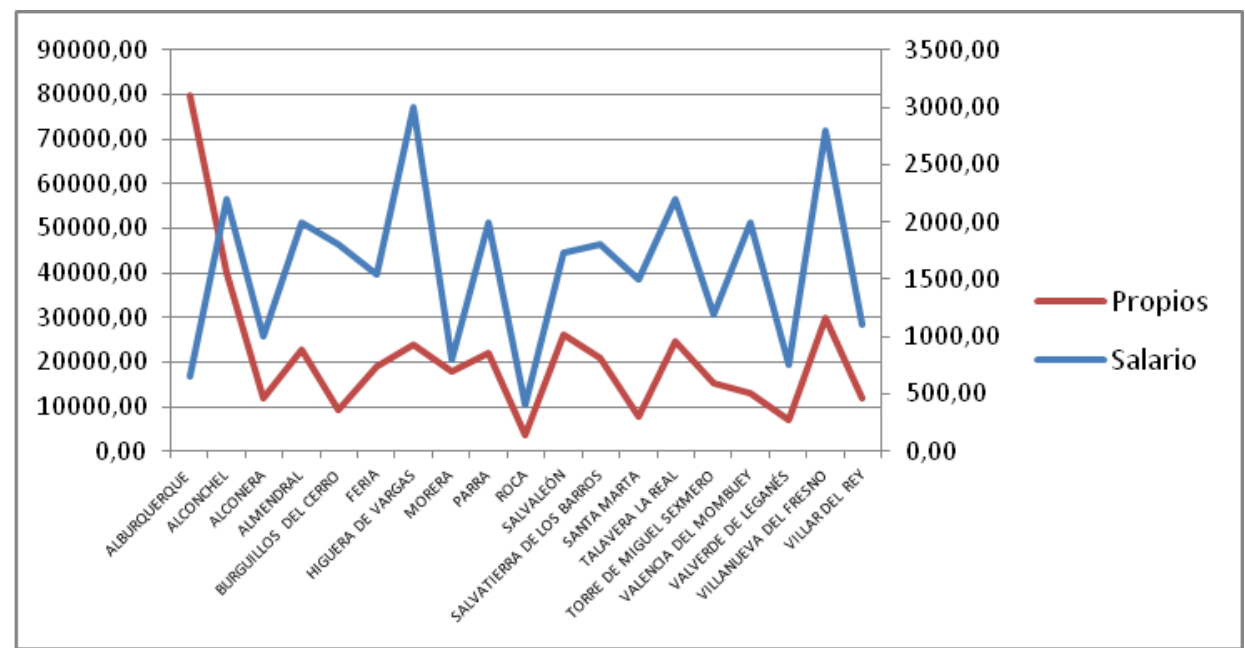

Figura 7. Partido de Badajoz: relación entre los salarios de los escribanos y los caudales de propios ${ }^{46}$.

En primer lugar, se perciben grandes diferencias de caudales públicos entre las distintas poblaciones del partido, que oscilan entre los 80.000 reales de Alburquerque ${ }^{47}$, y los 3.700 que dice tener Roca. En segundo lugar, y por el trazado de las líneas del gráfico, apreciamos que, en términos generales, existía una influencia real de dichos caudales en los salarios de los escribanos: en las localidades en las que los propios eran mayores, el dinero destinado a pagar a 
los escribanos del ayuntamiento (ya fueran uno o varios) aumentaba; y disminuía en aquéllas con menos dinero. Sin embargo, la diferencia entre ambos no era excesiva, es decir, los escribanos de pueblos con muchos propios cobraban generalmente un salario mayor, pero no mucho mayor, que los de poblaciones con menos dinero.

Por otra parte se aprecia que, a pesar de que influían claramente en el salario, los propios no eran determinantes: en el partido de Badajoz (y en todos los demás) hay casos de villas acaudaladas cuyos escribanos de ayuntamiento tenían un salario bajo (como Alburquerque, en el partido de Badajoz, con propios de 80.000 reales anuales y salario del escribano de 660 reales); y de pueblos pobres que pagaban un salario relativamente alto, al menos para los parámetros de su partido (caso de Santa Marta, también de Badajoz, con 7.902 reales anuales de propios y cuyo escribano cobraba 1.500 reales anuales).

El sueldo proporcionado por el ayuntamiento debía de aportar cierta estabilidad económica a los escribanos, pero resultaba corto para cubrir sus necesidades. Así, en las respuestas se hacen frecuentes referencias a que era escaso o claramente insuficiente. Este hecho explica que los escribanos que atendían el ayuntamiento se hicieran cargo de otros organismos locales, como el pósito o la alhóndiga, o/y de atender a los particulares en una escribanía pública. De esta forma, en los pueblos en los que existía un solo escribano, este solía encargarse de todos los aspectos que fueran necesarios $^{48}$. Por otra parte, en algunas poblaciones había un número excesivo de escribanos, de manera que al repartirse la clientela y las ganancias, faltaba dinero para que todos se mantuvieran dignamente ${ }^{49}$.

En cuanto a la cuantía de los salarios, percibimos que existe una gran variedad según el pueblo del que se trate. Para obtener conclusiones válidas en el conjunto de Extremadura, hemos separado las poblaciones con escribanos y las poblaciones con fieles de fechos (ambos como trabajadores de los ayuntamientos ${ }^{50}$ ) de cada uno de los nueve partidos, y hemos comprobado:

- los salarios de cada uno de ellos

- los caudales obtenidos de los bienes propios y de los arbitrios de cada una de dichas poblaciones

- el número de vecinos de cada población.

Por último, hemos obtenido los promedios de estas cifras, y con los datos resultantes se han elaborado varias tablas que nos ayudarán a analizar la información y a establecer las conclusiones pertinentes.

En primer lugar, comparamos los caudales de propios de los pueblos que tenían escribano de ayuntamiento con los que tenían fiel de fechos, en los distintos partidos:

\begin{tabular}{|l|c|c|}
\hline PARTIDO & $\begin{array}{l}\text { PROPIOS PUEBLOS CON } \\
\text { ESCRIBANOS }\end{array}$ & $\begin{array}{l}\text { PROPIOS PUEBLOS } \\
\text { CON FIELES }\end{array}$ \\
\hline Alcántara & $11.965,50$ & $1.864,10$ \\
\hline Badajoz & $21.452,16$ & $5.801,33$ \\
\hline Cáceres & $19.076,27$ & $2.800,00$ \\
\hline Coria & $71.28,47$ & $5.047,69$ \\
\hline La Serena & $12.356,23$ & $8.750,00$ \\
\hline Llerena & $19.500,83$ & $12.080,23$ \\
\hline Mérida & $11.735,00$ & $10.364,04$ \\
\hline Plasencia & $8.488,17$ & $2.102,44$ \\
\hline Trujillo & $11.054,10$ & $4.329,45$ \\
\hline
\end{tabular}

Tabla I. Caudales de propios en las poblaciones con escribanos y en las poblaciones con fieles de fechos (promedios, por partidos).

En los nueve partidos, las medias de los caudales de los pueblos con escribanos resultan claramente superiores a las medias de dichos propios en los pueblos con fieles. Con lo que concluimos que el caudal obtenido de los propios debía ser un factor importante a la hora de que un concejo contratase a un escribano, o bien tuviera que nombrar a un fiel de fechos para realizar las funciones necesarias.

Seguidamente, relacionamos los salarios de los escribanos con los caudales de propios que tenían las poblaciones en las que aquéllos trabajaban (siempre con el promedio de cada partido): 


\begin{tabular}{|l|c|c|}
\hline PARTIDO & MEDIA SALARIOS ESCRIB & MEDIA BIENES PROPIOS \\
\hline Alcántara & 804,42 & $11.965,50$ \\
\hline Badajoz & $1.605,05$ & $21.452,16$ \\
\hline Cáceres & 910,00 & $19.076,27$ \\
\hline Coria & 827,93 & $7.128,47$ \\
\hline La Serena & $1.081,62$ & $12.356,23$ \\
\hline Llerena & $1.083,48$ & $19.500,83$ \\
\hline Mérida & 893,67 & $11.735,00$ \\
\hline Plasencia & $1.162,27$ & $8.488,17$ \\
\hline Trujillo & $1.012,27$ & $11.054,10$ \\
\hline
\end{tabular}

Tabla III. Salarios de los escribanos y caudales de propios (promedios, por partidos).

Observamos que existe una relación entre los partidos con mayores propios y los que tienen escribanos con mejores salarios. Si comprobamos casos concretos, advertimos que Badajoz, Llerena y La Serena eran tres de las cinco demarcaciones cuyos pueblos tenían mejores propios, y coincide que pagaban también los mayores salarios a sus escribanos de ayuntamiento; mientras que Coria era uno de los partidos con menor media de propios, y sus escribanos también cobraban un salario menor.

Sin embargo, y a pesar de que la influencia entre ambos conceptos parece clara, no siempre coinciden mayores propios con mayores salarios y menores propios con menos salario. Es el caso de Plasencia, que con una media de propios relativamente baja, pagaba a sus escribanos más que otros partidos más ricos.

Debemos indicar que los datos anteriores se refieren exclusivamente a los escribanos de los ayuntamientos, y a la cuantía económica que dedicaban dichos organismos a pagar sus servicios. Es una cuestión diferente su trabajo como escribanos públicos, en el que cobraban por la realización de determinados escritos o actos jurídicos. En este caso, para evitar abusos, existían unas tarifas o derechos oficiales, (los aranceles) que establecían la cuantía a pagar por cada uno de esos actos ${ }^{51}$. En cualquier caso, esta fuente económica era fundamental para los escribanos, pues solía suponer la mayor parte de sus beneficios; tanto más para aquéllos que se dedicaban únicamente a la escribanía pública.

\section{CONCLUSIONES}

Del análisis de los resultados se extraen las siguientes conclusiones:

1. La proporción de poblaciones que contaban con escribano era alta en la mayor parte de los partidos extremeños. Destacaban los de Llerena (donde había en el $90 \%$ de los pueblos) y La Serena (en el 82\%). Su número también era considerable en Badajoz, Cáceres, Plasencia y Trujillo (donde rondaban el 70\%); mientras que en el extremo opuesto se hallaban los territorios de Alcántara y Coria, que tenían tan solo un $50 \%$ de pueblos con escribanos.

2. En cuanto a tipología, predominaban claramente los escribanos numerarios. En segundo lugar, aunque a distancia, se cuentan los escribanos reales y por último los de las órdenes.

3. En torno a las actuaciones escribaniles se perciben algunos problemas que se repiten en las respuestas de varias poblaciones. Estos problemas son: la concepción patrimonial de la documentación pública que llegaban a tener algunos escribanos, la pérdida o extravío de los documentos y la realización de prácticas poco éticas.

4. En términos generales, el caudal obtenido de los bienes de propios resultaba un factor importante para que un ayuntamiento pudiese contratar a un escribano o bien tuviese que nombrar a un fiel de fechos, siempre menos costoso. En ocasiones se recurría a soluciones alternativas, como compartir escribano con otra población o llamar al de un municipio vecino de forma puntual, cuando era imprescindible.

5. Los escribanos solían tener un salario que doblaba (y en algunos casos triplicaba) el que cobraban los fieles de fechos. Este hecho se explica porque los primeros tenían titulación oficial, así como mayor formación y por tanto más facultades y atribuciones que los segundos.

6. En términos generales, se puede afirmar que los caudales de propios que recababa cada población influían en la cuantía de los salarios a sus escribanos de concejo, de forma que a mayores caudales correspondían mejores salarios y viceversa. Así, Badajoz, Llerena y La Serena eran tres de los partidos cuyos pueblos gozaban de mejores propios y también los que pagaban mejor a sus escribanos; mientras que Coria era uno de los partidos con menores propios y sus escribanos cobraban un salario menor. No obstante, hay excepciones, como ocurre en el 
partido de Plasencia, donde los propios eran en general bajos, pero se pagaba a los escribanos un salario mayor que en otros territorios más ricos.

\section{NOTAS}

1 Ejemplos de actos entre particulares eran: venta, cambio, donación, censos, préstamos, arrendamientos, contratos de trabajo, fletamiento de barcos, compañías o asociaciones, contratos de parcería, inventarios post-mortem, cancelación de deudas, escrituras de matrimonio, de dote, de donación, de arras, de capital, etc. Véase: REDER GADOW, M. Breve estudio sobre los escribanos públicos malagueños a comienzos del siglo XVIII. Baetica, 1982, vol. 5, p. 201.

2 No es nuestro objetivo realizar aquí un análisis exhaustivo sobre los escribanos diferente a lo ya realizado, sino proporcionar una breve introducción al objeto de nuestra investigación, que es la presencia de esta figura en Extremadura a través de una fuente documental como es el interrogatorio de la Audiencia.

3 Por la Pragmática de 7 de junio de 1503, dictada por los Reyes Católicos, según la cual los escribanos tenían la obligación de conservar los protocolos, así como la de recoger en ellos el texto completo de cada escritura que autorizaran. Esto representa el nacimiento del protocolo notarial. Véase al respecto: Novísima recopilación de las leyes de España dividida en XII libros [...] mandada formar por el Señor Don Carlos IV [en línea]. Madrid, 1805. Disponible en: 〈http://bvpb.mcu.es/es/consulta/registro.cmd?id=403945> [Consulta: 21 de marzo de 2014]. El texto al que hacemos referencia se encuentra en el Tomo V, Libro X, Título XXIII, Ley I.

${ }^{4}$ Las leyes que recogen los requisitos necesarios se encuentran recogidas en la Novísima recopilación de las leyes de España. Véase: NOVÍSIMA recopilación de las leyes de España dividida en XII libros [...] mandada formar por el Señor Don Carlos IV. Madrid, 1805. Las leyes referentes a "los escribanos públicos y del número de los pueblos, notarios de los reinos y sus visitas" se ubican en el Tomo III, Libro VII, Título XV.

${ }^{5}$ Su trabajo era similar al que realizan los actuales secretarios de ayuntamiento.

6 También existían los escribanos de cámara de las audiencias o los escribanos eclesiásticos, a quienes no nombramos porque no aparecen en el interrogatorio.

${ }^{7}$ Hasta entonces, este territorio dependía de las chancillerías de Valladolid y de Granada.

${ }^{8}$ Comenzó en 1528 y se extendió hasta 1558 , aunque los datos siempre estaban referidos a 1527 y 1528 . La mayor parte de los interrogatorios y censos que citamos se extienden a lo largo de varios años.

${ }^{9}$ Como es natural, existe una amplia bibliografía de todos los censos e interrogatorios mencionados. Como ejemplo representativo, sobre el Censo de Pecheros podemos citar a CARANDE TOVAR, R. Carlos V y sus banqueros. Barcelona: Crítica, 2000; y CARRETERO ZAMORA, J.M. La Averiguación de la Corona de Castilla, 1525-154: los buenos vecinos pecheros y el dinero del reino en época del emperador Carlos V. Valladolid: Junta de Castilla y León, 2009. Sobre las Averiguaciones de Felipe II a CAMPOS Y FERNÁNDEZ DE SEVILLA, F.J. Las relaciones topográficas de Felipe II: índices, fuentes y bibliografía. Anuario jurídico y económico escurialense, no 36, 2003, p. 439-574. Sobre el Vecindario de la Sal, a LANZA GARCÍA, R. El vecindario de 1683: una fuente inédita para el estudio de la población de la Corona de Castilla. Revista de Historia Económica, vol. 23, n ${ }^{\circ}$ 2, p. 335-369. Sobre el Censo de Campoflorido, a BUSTELO GARCÍA DEL REAL, F. El vecindario general de España de 1712-1717 o Censo de Campoflorido. Revista Internacional de Sociología, vol. XXXII, no 7-8, 1973, p. 83-103; y El vecindario general de España de 1712-1717 o Censo de Campoflorido (2). Revista Internacional de Sociología, vol. XXXIII, no 11 -12,1974, p. 735. En torno al Catastro de Ensenada, a CAMARERO BULLÓN, C. El Catastro de Ensenada: magna averiguación fiscal para alivio de los Vasallos y mejor conocimiento de los Reinos. 1749-1756. Madrid: Ministerio de Hacienda, Dirección General del Catastro, 2002; y a JIMÉNEZ SERRANO, B. y SERRANO GUTIÉRREZ, J.M. El Catastro del Marqués de la Ensenada en el antiguo Reino de Granada. Granada: Junta de Andalucía, Consejería de Cultura, 2004. Sobre el Censo de Aranda a VILAR RAMÍREZ, J.B. El censo de Aranda en el Obispado de Orihuela: aproximación a la demografía valenciana moderna. Anales de Historia Contemporánea, no 1, 1982, p. 271-277; y PÉREZ SARRIÓN, G. El censo de Floridablanca en Aragón: un análisis general. Revista de Historia Económica, n ${ }^{\circ}$ 2, 1984, p. 263-286. Y sobre el Censo de Floridablanca, a PÉREZ MOREDA, V. La estadística demográfica en el gobierno de la España ilustrada: recuerdo y elogio del Censo de Floridablanca. Índice, $\mathrm{n}^{\circ}$ 43, 2010, p. 8-17.

${ }^{10}$ Gracias a su diversidad temática, el interrogatorio se ha utilizado para realizar numerosos trabajos de investigación.

${ }^{11}$ Esto último se dispuso, probablemente, para proporcionar mayor credibilidad a los datos.

${ }^{12}$ La estructura de las respuestas a los interrogatorios, los informes y la información adicional que se da en cada caso es diferente en los distintos partidos; aunque, como es natural, las preguntas son las mismas para todos.

13 Véase: Archivo Histórico Provincial de Cáceres. Real Audiencia, Audiencia Territorial y Provincial. Ref. ES.10037.AHP/2. Fecha 1790/1834.

14 El orden en que exponemos estos recursos metodológicos no responde a su importancia, sino más bien a la organización lógica de la investigación: en primer lugar hemos elaborado la base de datos e incorporado en ella los textos seleccionados del interrogatorio; posteriormente hemos sometido dichos textos a análisis documental y por último hemos analizado los datos desde un punto de vista histórico.

15 Se ha escogido este coeficiente tras revisar los asignados por diversos autores especialistas en la historia moderna de Extremadura, como son: MELÓN JIMÉNEZ, M.A. Extremadura en el Antiguo Régimen: economía y sociedad en tierras de Cáceres, 1700-1814. Mérida: Editora Regional de Extremadura, 1989, p. 30. RODRÍGUEZ SÁNCHEZ, A. La investigación en demografía histórica en Extremadura: siglo XVI a 1850. En: Demografía histórica en España. Madrid: El Arquero, 1988, p. 290; BUSTELO GARCÍA DEL REAL, F. La transformación de vecinos en habitantes: el problema del coeficiente. Revista de estudios geográficos, no 130, 1973, p. 154-164, p. 164; REY VELASCO, F. Historia económica y social de Extremadura a finales del Antiguo Régimen. Badajoz: Universitas, 1983, p. 90.

${ }^{16}$ Es preciso indicar que, tanto en las preguntas seleccionadas como en los textos extraídos del interrogatorio (que incluimos en cursiva), hemos procurado mantener la forma de expresión utilizada originalmente, incluyendo acentuación y errores ortográficos o tipográficos. Solo se han corregido cuando creemos que pueden dificultar la comprensión del texto.

${ }^{17}$ El texto completo de la pregunta $\mathrm{n}^{\circ} 2$ es el siguiente: "Si el Pueblo es Realengo, de behetría, ó hay mitad de oficios; si es de Señorío, á quién pertenece; y en este caso, si el dueño lo es solo de la jurisdicion, ó de parte del terreno; en qué forma se hace la elección de sujetos para la administración de justicia, y gobierno, el número de éstos, y si hubiese Corregidor ó Alcalde Mayor, si tienen comisiones, ó subdelegaciones, qué salario, y emolumentos perciben, y de qué fondos se les paga; si los Alcaldes son pedáneos, de qué causas conocen, en qué forma, y hasta que cantidad se estiende su conocimiento; qué número hay de Abogados, de Procuradores y Escribanos, y si son Reales ó Numerarios; si con respecto al vecindario sobran ó faltan, y el número de todos los subalternos, expresando su salario, si le tienen, y qué arancel se observa en los 
juzgados". Véase: Interrogatorio formado por orden del Consejo, para la visita de la provincia de Extremadura, que deben hacer el regente y ministros de la Real Audiencia, creada en ella antes de su apertura [en línea]. Madrid: Oficina de la viuda de Marin, 1791, h. 1. Disponible en: <https://books.google.es/books?id=rAnxqTDA7VkC\&printsec=frontcover\&hl=es\&source=gbs_ge_summary_r\&cad=0\#v=onepage\&q\&f=false> [Consulta: 15 de marzo de 2018]. Aunque aquí referenciamos la fuente original, es conveniente indicar que en todos los volúmenes impresos del interrogatorio se incluye el texto de las 57 preguntas que lo componían.

18 Véase: Ibid., h. 2

${ }^{19}$ Lamentablemente, gran parte de la documentación del partido de Mérida ha desaparecido: solo se conserva la de 15 poblaciones de las 40 que formaban esta demarcación. En consecuencia, los datos referentes a Mérida no pueden ser completos, y no se tienen en cuenta al realizar el análisis. Para diferenciar este hecho, hemos atenuado el color de la columna correspondiente, en este y sucesivos gráficos.

${ }^{20}$ Se ha de tener en cuenta que en algunos municipios había más de un escribano. En casos extremos el número era alto, como, por ejemplo, en las ciudades de Badajoz (15 escribanos), Plasencia (11) o Jerez de los Caballeros (8)

21 Así, en la respuesta de Robledillo (partido de Trujillo), se indica: "El no haber escribano es por los pocos emolumentos y ser aldea". En esta y sucesivas citas textuales tomadas del interrogatorio no hemos incluido la referencia completa; esto se debe a que repetiríamos una y otra vez la misma referencia, aunque cambiando el tomo y la página. Creemos que puede bastar con la indicación del partido al que pertenece la localidad (puesto que los tomos se organizan por partidos) y la población, fácilmente localizable por su ordenación alfabética en cada tomo.

22 Badajoz y Jerez de los Caballeros.

23 Sucede de esta forma en La Guarda (partido de La Serena), donde actúa el escribano de Campanario (del mismo partido), y se le pagan de propios por reglamento 300 reales; en su ausencia hay un fiel de fechos. También en Corchuelas, donde asiste el escribano de Torrejón (ambos del partido de Plasencia) a cambio de 300 reales anuales. Y en Millanes, pueblo que atiende "para los asuntos que ocurren" uno de los dos escribanos que hay en el concejo de la Mata y que reside en Navalmoral (las tres de Plasencia); por este trabajo se le pagan 160 reales anuales. En Arroyomolinos de León (Llerena), donde hay un fiel de fechos para el ayuntamiento, el escribano reside en Segura (Plasencia), "pues a motivo del corto vecindario no puede aquí mantenerse alguno de continuo sin mucho perjuicio de estos vecinos". En Cañaveral de León se recurre al escribano de Fuentes de León (ambos del partido de Llerena) para que atienda su ayuntamiento, a cambio de 360 reales y también se hace cargo de la escribanía pública; etc.

24 También en Fuente la Lancha (Trujillo), Araya (Alcántara), Cañaveral de León (La Serena), etc.

25 También comparten escribano Casas del Castañar y Asperilla (partido de Plasencia); Casas del Monte, Segura y Gargantilla (Plasencia); Mesas de Ibor (Plasencia) y Fresnedoso (Trujillo); Talaveruela y Valverde de la Vera (Plasencia); Torbiscoso, Peraleda (ambas de Plasencia) y otras villas; Belvis, Valdehúncar y Valdecañas (todas del partido de Plasencia); Huélaga y Calzadilla (Coria), etc.

26 Así sucede, por ejemplo, en Malpartida (partido de La Serena): "Que no hay [...] mas que escribano aprobado para el territorio de las ordenes, que despacha el juzgado y lo publico, y un fiel de fechos para el ayuntamiento, dotado este con trescientos veinte reales en el fondo de propios...". O en Garlitos (Trujillo), donde se dice: "Que en el hay [...] escribano numerario uno, y un fiel de fechos de su aiuntamiento [...]. Tiene de salario el de aiuntamiento asignado por el relamento del Consejo ochenta ducados anuales, que cobra caso de haverlos de sus propios y arbitrios".

27 Recordemos que no se han podido contabilizar los escribanos de la mayor parte de las poblaciones del partido de Mérida. Esto probablemente influye en el número de escribanos de las órdenes militares, puesto que la mayoría del territorio de dicho partido pertenecía a la Orden de Santiago.

${ }^{28}$ El visitador del partido de Plasencia indica que también hay un número excesivo de escribanos en Serradilla, Serrejón, Jarandilla, Garganta La Olla... Esto mismo afirman las justicias de Llerena, Segura de León (Llerena), etc.

${ }^{29}$ Estos abusos ya fueron objeto de críticas en la literatura de la época, sobre todo en la novela picaresca. Véanse al respecto: ALAMILLO SANZ F.J. La administración de Justicia en los clásicos españoles. Madrid: Civitas, 1996; BERMEJO CABRERO, J.L. Justicia penal y teatro barroco. En: Sexo barroco y otras transgresiones premodernas. Madrid: Alianza Universidad, 1990, p. 91-108; NAVARRO BONILLA, D. Todo por escrito: prácticas administrativas y conciencia documental en la España Moderna. Boletín de la ANABAD, 2012, vol. LIII, n ${ }^{\circ} 1$, p. 91-11; SCHWARZ, L. El letrado en la sátira de Quevedo. Hispanic Review, 1986, vol. 54, p. 27-46.

${ }^{30}$ Sucede lo mismo en otras poblaciones como Villalba (partido de Badajoz), Solana (Badajoz), Mata (Alcántara), etc.

${ }^{31}$ En el mismo sentido se manifiestan el visitador de Guadalcanal (partido de Llerena) y las autoridades de Valencia de Alcántara (Alcántara).

32 Como en Garlitos (partido de Trujillo), Malpartida (La Serena), Cabeza la Vaca (Llerena), etc.

33 Así sucedía en varias poblaciones del partido de Trujillo, donde predominaba el régimen señorial: Tamurejo, Miajadas, Villarta de los Montes, Fresnedoso, Deleitosa, Mohedas, etc., y también en algunas poblaciones de Badajoz, como Atalaya o Cheles.

34 Citamos, como ejemplos, los siguientes casos: en Esparragosa de Lares (La Serena), el escribano sirve al ayuntamiento, juzgado y la escribanía pública de la villa; en La Haba (La Serena) se dice que "ejerze todas las escribanías"; en Fuentes de León (Llerena), el escribano lo es de ayuntamiento, del juzgado y público: en Pasarón (Plasencia) es del ayuntamiento y comisiones; etc.

35 Por ejemplo en Zahinos (Badajoz), Guijo de Coria (Coria), Hoyos (Coria), Peñalsordo (Trujillo), Villarta de los Montes (Trujillo), Barcarrota (Badajoz), Arroyomolinos de León (Llerena), etc.

${ }^{36}$ Y continúa la respuesta: "por lo que sería útil se recojiesen y colocasen con separación de escribanías en un archivo publico y bajo tres llaves...".

${ }^{37}$ La normativa de la época exigía a los aspirantes al oficio ser hombres de "poridad", honestos y bien considerados en sus lugares de origen. Así, "se les exigía que fuesen personas que supiesen escribir bien, libres, cristianos de buena fama, entendidos en el arte de la escribanía, vecinos y hombres de poridad" Véase: Cózar Gutiérrez, 2010, p. 273

38 Marchant Rivera cita, en relación con este tema, a TOWSEND, J.: Viaje por España en la época de Carlos III (1786-1787), Madrid, Turner, 1988.

${ }^{39}$ Para más información sobre delitos cometidos por los escribanos, véase Extremera Extremera, 2005, p. 465-484

40 Extremera hace referencia a la Nueva Instrucción de 1788, dada a corregidores y alcaldes mayores, que dice: "Deberá ser una de las más principales obligaciones de los Corregidores el velar incesantemente, por sí y por medio de las Justicias, sobre la conducta de todos los escribanos de su distrito, para evitar que susciten y fomenten pleitos y criminalidades, como sucede muy frecuentemente por el interés que de ello les resulta". 
41 A la corrupción de los cargos públicos hacen referencia las respuestas de los párrocos o/y los informes de los visitadores de: Cañaveral y Casar de Cáceres (del partido de Cáceres); Campanario, Castuera, Esparragosa de Lares, La Coronada, Magacela, etc. (La Serena); Casas de Reina y Valencia del Ventoso (Llerena); Casatejada, Cuacos, Jaraiz y Peraleda de la Mata (Plasencia); y Piedras Albas, Villa del Campo y Carbajo (Alcántara). El partido en el que se comentan más casos de corrupción era La Serena.

42 Así se explica en la respuesta de Viandar (Plasencia) a la pregunta $\mathrm{n}^{\circ}$ 2. También en Valverde de la Vera (Plasencia), donde se habla del escribano de ayuntamiento: “a quien le paga anualmente este concejo y por el despacho de los negocios de propios y arbitrios y villa, en razón de ellos, un mil reales, y lo demás de causas y otros que despacha, sus salarios son con arreglo al último real arancel expedido y aprobado por la dicha Real Chancilleria de Balladolid...".

${ }^{43}$ Algunos pueblos que carecían de propios, o cuyas rentas eran insuficientes, recurrían al reparto de los gastos comunes entre los vecinos. Así sucede en Torrejón el Rubio (Plasencia), Ribera de Oveja (Coria) o Madroñera (Trujillo), según se indica en las respuestas que dan a la pregunta $\mathrm{n}^{\mathrm{o}} 12$.

44 Lamentablemente, carecemos de los datos de ciertas poblaciones de gran interés. Así sucede, por ejemplo, en la ciudad de Badajoz, de la que sabemos que disponía de 110.000 reales anuales de los propios y arbitrios, pero ignoramos los salarios que percibían los escribanos de su ayuntamiento, por lo que no se puede establecer la relación entre ambas variables.

45 Para representar los datos, en este caso y en otros similares (referidos fundamentalmente a la relación entre los caudales de propios y los salarios) que incluiremos a lo largo del apartado "Resultados", hemos escogido los gráficos de líneas. Aunque no existe aquí la variable temporal, creemos que es la forma gráfica en la que se aprecian mejor las oscilaciones de las cantidades; y, sobre todo, permite ver con facilidad las coincidencias o diferencias entre las trayectorias de los dos conceptos representados mediante dos ejes distintos.

46 En este gráfico (y en otros del mismo tipo que iremos adjuntando) se establecen dos variables: caudales de propios y salarios de los escribanos. Como las cantidades que se miden son muy diferentes, hemos establecido dos ejes, cada uno de los cuales sirve para cuantificar una variable. Son las siguientes:

- Línea roja, con escala en el eje izquierdo (de 0 a 90.000): cantidad obtenida de los bienes de propios (y de los arbitrios si estos existían) en las poblaciones del partido de Badajoz. Se cuenta en reales vellón por año.

- Línea azul, con escala en el eje derecho (de 0 a 3.500): salario asignado por los ayuntamientos a los escribanos en los municipios del partido de Badajoz. Se cuenta en reales vellón por año.

De esta forma, podemos ver con facilidad las variaciones de las líneas, y comprobar si hay relación entre ambas.

47 Según manifiesta en su respuesta, la ciudad de Badajoz obtenía 110.000 reales de los propios, pero no se incluye en el gráfico porque no conocemos el salario de sus escribanos de ayuntamiento.

48 En Moraleja (Alcántara) se dice que "hay un solo escribano para numero y ayuntamiento"; en Navas del Madroño (Alcántara): "hay un escribano real de ordenes publico numerario y de su aiuntamiento"; en Santibáñez el Alto (Alcántara): "solo ai un escribano que haze de ayuntamiento y numerario"; etc.

49 Así se afirma en las respuestas de Valverde del Fresno, (Alcántara), Escurial (Trujillo), Garrovillas (Cáceres), etc.

50 Ambas figuras son excluyentes en el ayuntamiento: el concejo que tiene escribano/s, no tiene un fiel de fechos y viceversa. Por otra parte, siempre hemos encontrado un único fiel de fechos en el ayuntamiento, mientras que puede haber más de un escribano (si bien hay muy pocos casos).

51 En relación con los aranceles, las respuestas al interrogatorio muestran información variada y confusa. En esta época se aplicaban aranceles diferentes, de forma que los escribanos de cada pueblo se atenían al más común en su zona, al que siempre se había utilizado o incluso no se atienen a ningún arancel, sino que siguen "la costumbre". Así, se hace referencia al arancel de la Real Chancillería de Granada de 1722, al de 1745, al de la Cartilla Real de escribanos de 1751, al arancel de la Chancillería de Valladolid, etc. Existe, además, la dificultad de que en las respuestas se nombra de distintas formas a un mismo arancel, haciendo difícil su identificación.

\section{BIBLIOGRAFÍA}

ALAMILlO SANZ, F.J. La administración de justicia en los clásicos españoles. Madrid, Civitas, 1996.

ALEJANDRE GARCÍA, J.A. Estudio histórico del delito de falsedad documental. Anuario de Historia del Derecho Español, 1972, vol. XLII, p. 175-178.

BERMEJO CABRERO, J.L. Justicia penal y teatro barroco. En: Sexo barroco y otras transgresiones pre-modernas. Madrid: Alianza Universidad, 1990, p. 91-108.

BOUZA ÁLVAREZ, F.J. Del escribano a la biblioteca: la civilización escrita europea en la Alta Edad Moderna (siglos XV-XVII). Madrid: Síntesis, 1997.

BUSTELO GARCÍA DEL REAL, F. La transformación de vecinos en habitantes: el problema del coeficiente. Revista de estudios geográficos, 1973, nº 130, p. 154-164.

CASTILLO LÓPEZ, A. Cultura escrita y actividad escribanil en el Siglo de Oro. En: Villalba, E., Torné, E. (eds.) El nervio de la República: el oficio de escribano en el Siglo de Oro. Madrid: Calambur, 2010, p. 351-370.

CÓZAR GUTIÉRREZ, R. "De lo que yo el infraescripto escribano doy fe": los escribanos de la villa de Albacete durante el siglo XVIII. Revista de Historia Moderna, 2010, n 28, p. 269-299.

EXTREMERA EXTREMERA, M.A. El delito en el archivo: de escribanos, falseadores y otras gentes de mal vivir en la Castilla del Antiguo Régimen. Hispania, 2005, vol. LXV, nº 220, p. 465-484.

EXTREMERA EXTREMERA, M.A. Los escribanos en Castilla en la Edad Moderna: nuevas líneas de investigación. Chronica Nova, 2001, no 28, p. 159-184.

EXTREMERA EXTREMERA, M.A. La pluma y la vida: escribanos, cultura escrita y sociedad en la España moderna (siglos XVI-XVIII). Litterae, 2004, nº 3-4, p. 287-306. 
GUERRA GUERRA, A. Escribanos badajocenses del siglo XVII. Revista de estudios extremeños, 1977, vol. XXXIII, $\mathrm{n}^{\mathrm{o}} 1$, p. 5-68.

INTERROGATORIO formado por orden del Consejo, para la visita de la provincia de Extremadura, que deben hacer el regente y ministros de la Real Audiencia, creada en ella antes de su apertura [en línea]. Madrid: Oficina de la viuda de Marin, $1791 . \quad$ Disponible en: <https://books.google.es/books?id=rAnxqTDA7VkC\&printsec=frontcover\&hl=es\&source=gbs_ge_summary_r\&c $\mathrm{ad}=0 \# \mathrm{v}=$ onepage $\& \mathrm{q} \& \mathrm{f}=$ false $>$ [Consulta: 15 de marzo de 2018].

LORENZO CADARSO, P.L. Cláusulas y formulismos en la documentación judicial castellana de los siglos XVI y XVII. Signo, 1999, nº 6, p. 205-221.

LORENZO CADARSO, P.L. La correspondencia administrativa en el estado absoluto castellano (ss. XVI-XVIII) [en línea]. Tiempos modernos, 2001, vol. 2, $\mathrm{n}^{\mathrm{o}}$ 5, p. 1-29. Disponible en: <http://www.tiemposmodernos.org/tm3/index.php/tm/article/view/15/29> [Consulta: 12 de enero de 2019].

LOSA CONTRERAS, C. El escribano del Concejo: semblanza de un oficio municipal en el Madrid de los Reyes Católicos. En: Villalba Pérez, E., Torné Valle, E. (ed. lit.). El nervio de la república: el oficio de escribano en el Siglo de Oro. Madrid: Calambur, 2010, nº 28, p. 293-312.

MARCHANT RIVERA, A. Los escribanos españoles del siglo XVIII a la luz de la literatura de viajes: viaje por España de Joseph Towsend. Baetica: estudios de arte, geografía e historia, 2006, vol. 28, no 2, p. 325-336.

MELÓN JIMÉNEZ, M.A. Extremadura en el Antiguo Régimen: economía y sociedad en tierras de Cáceres, 1700 1814. Mérida: Editora Regional de Extremadura, 1989.

NAVARRO BONILLA, D. Todo por escrito: prácticas administrativas y conciencia documental en la España Moderna. Boletín de la ANABAD, 2012, vol. LIII, nº 1, p. 96-99.

NOVÍSIMA recopilación de las leyes de España dividida en XII libros [...] mandada formar por el Señor Don Carlos IV [en línea]. Madrid, 1805. Disponible en: <http://bvpb.mcu.es/es/consulta/registro.cmd?id=403945> [Consulta: 21 de marzo de 2017].

REY VELASCO, F. Historia económica y social de Extremadura a finales del Antiguo Régimen. Badajoz: Universitas, 1983.

RODRÍGUEZ CANCHO, M. y BARRIENTOS ALFAGEME, G. (dirs.). Interrogatorio de la Real Audiencia: Extremadura a finales de los tiempos modernos. Mérida: Asamblea de Extremadura, 1993-1996.

RODRÍGUEZ SÁNCHEZ, A. La investigación en demografía histórica en Extremadura: siglo XVI a 1850. En: Demografía histórica en España. Madrid: El Arquero, 1988, p. 290.

SOLANO MACÍAS, C. y VIVAS MORENO, A. La cultura escrita en Extremadura a finales del s. XVIII a través del Interrogatorio de la Real Audiencia. Gijón: Trea, 2018.

SCHWARZ, L. El letrado en la sátira de Quevedo. Hispanic Review, 1986, vol. 54, p. 27-46.

TOWSEND, J. Viaje por España en la época de Carlos III (1786-1787). Madrid: Turner, 1988.

VILLALBA PÉREZ, E. Sospechosos en la verdad de lo que pasa ante ellos: los escribanos de la Corte en el Siglo de Oro: sus impericias, errores y vicio. Litterae: cuadernos de cultura escrita, 2002, vol. II, no 2, p. 121-150.

VILLALBA PÉREZ, E. y TORNÉ, E. El nervio de la república: el oficio de escribano en el Siglo de Oro. Madrid: Calambur, 2010.

ZOZAYA MONTES, L. De papeles, escribanías y archivos: escribanos del concejo de Madrid (1557-1610). Madrid: CSIC, 2011. 